\title{
Modeling and Forecasting Currency in Circulation in Sri Lanka
}

\author{
Rupa Dheerasinghe ${ }^{1}$
}

\begin{abstract}
Currency in circulation is typically estimated either by specifying a currency demand equation based on the theory of transaction and portfolio demand for money or univariate time series models. The first approach works well with low frequency data but faces limitations with high frequency data series. Therefore, this paper proposes an alternative approach in modeling the high frequency data series by decomposing the trend, the seasonal, and the cyclical components. Three separate models were estimated with monthly, weekly and daily time series, assembling tools for forecasting trend, seasonal patterns and cycles in individual series separately. Trend and seasonal effects were identified by regressing on trend and seasonal dummies while cyclical dynamics were captured by allowing for ARMA effect in the regression disturbances. The sample period is 1 January 2000 to 31 August 2005 and data for 1 September 2005 to 31 January 2006 were used for post validity test. All three models fit the data well and provide very close forecasts during the post sample period. All three models clearly identify both inter-month and intramonths variations of currency in circulation. The models also identified that the Sinhala/Tamil New Year, elections, Christmas and the day prior to public and bank holidays have significant positive impact on demand for currency in Sri Lanka. This methodology may be used in forecasting currency in circulation with careful assessment of day to day current developments in the economy.
\end{abstract}

\section{Introduction}

The Central Bank of Sri Lanka (CBSL) has been conducting its monetary policy within a framework of targeting monetary aggregates, in which reserve

1/ The author wishes to express her sincere gratitude and thanks to Dr. D.S. Wijesinghe, Director, Domestic Operations Department and Dr. P.W.R.B.A.U. Heart, Alternative Executive Director, IMF for their valuable comments and suggestions on the first draft of this paper. 
money is the operating target. Reserve money consists of the balances held by commercial banks with the Central Bank under the Statutory Reserve Requirement (SRR) and currency in circulation. In Sri Lanka, currency in circulation accounts for more than 65 per cent of the total reserve money, indicating its importance in overall monetary management. Within the existing framework, monetary policy operations are conducted to achieve a path of reserve money targets, while maintaining interest rates stable around a rate consistent with the path of reserve money targets. Under the current system of active Open Market Operations (OMO) $)^{2}$, an implicit interest rate is achieved by appropriately managing market liquidity, in particular, by adjusting the volume of liquidity absorbed or injected through the auctions. Therefore, this system requires an accurate assessment of the daily liquidity position in the banking system.

The liquidity of the banking system is influenced by several autonomous factors, which are beyond the direct control of the Central Bank and the banking system. The most important autonomous factors are the government's net borrowings from the Central Bank and other banks, foreign exchange transactions with the Central Bank and the amount of banknotes and coins in circulation. A change in these factors injects or absorbs liquidity. Therefore, it leads to fluctuations in the liquidity position in the banking system. The currency in circulation comprises the outstanding amount of banknotes and coins held by the public and banks, which is determined by the cash demand of both the public and the banking system. Given this background, a systematic study of both short and long run variations in currency demand is extremely important for the banking system, in particular, to the Central Bank.

The availability of an accurate assessment of currency demand would enable the Central Bank to plan monetary policy strategies in advance to manage liquidity efficiently, to stabilize the money market in the short run and to maintain the target monetary growth in the long run. Such an assessment would also help the banking system to estimate the currency demand more accurately thus leading to an improvement in the cash flow management. Existing studies in Sri Lanka have mainly focused on modeling money demand functions with annual and quarterly time series. No studies are available of attempts to examine the behaviour in currency in circulation, even with annual data. However, given the recent changes in monetary policy operation techniques, which require close monitoring of money market liquidity, it is extremely important to study the variation in currency in circulation beyond quarterly or monthly frequencies. Therefore, this study attempts to apply modern techniques in the area of modeling and forecasting time series to

2/ The system of active open market operations was introduced by the CBSL on 3 March 2003, aiming at managing market liquidity actively at its own discretion. 
understand the daily, weekly, monthly behavioural patterns and to develop a model suitable for short term forecasting of the currency in circulation in Sri Lanka. The model and the findings of the study could be used for monitoring and assessing the liquidity position in the market and planning for liquidity management through open market operations. Section 2 of the paper provides the theoretical aspects of the modeling process and model specifications. Section 3 presents the outcomes of the modeling exercises, while Section 4 provides economic justifications. Section 4 concludes the paper with observations and recommendations.

\section{Methodology, Data and Model Specification}

\section{A. Theory, Data and Limitations}

In general, two types of statistical techniques are used in modeling and forecasting. One approach is the estimation through a standard currency demand function based on the theory of transactions and portfolio demand for money. Such an equation is estimated in isolation or as a part of a macro economic model. Explanatory variables commonly used in such an equation are income, price levels and interest rate to represent the opportunity cost of holding currency. The other approach is based on univariate time series models. In the literature, both approaches are used extensively in modeling annual and quarterly data series. However, the first approach is rarely used in modeling series with high frequencies i.e., beyond quarterly data. This is mainly due to the non availability of income data with high frequencies. It is also difficult to find a proxy for income with frequencies beyond monthly data. Theoretically, univariate models could be applied to any frequency (i.e., monthly, weekly or daily). Nevertheless, the specification of these models with high frequency data is somewhat difficult due to certain factors which are common to any country. Some of these difficulties are discussed below.

- In any economy, intra-month or intra-week variations may change from week to week or month to month. For example, the second and third weeks of April are significantly different from any other month in a year due to the Sinhala/Tamil New Year festival effect in these two weeks in April. Similar differences are common within the months as well.

- Modeling the effect of a particular day in two different years, is rather difficult because of holidays and variations in lag effects. This problem is most pronounced in analyzing daily or weekly data series. For example, if weekly data are used, it is well known that demand for currency is high in the Christmas week and the week prior to the Christmas week. In 2002, 
the week prior to the Christmas week ended on 22 December (Sunday), in 2003, on 21 December, in 2004, on 19 December etc. Univariate time series models will not be able to capture the effect of one or two extra days in weekly models. This nature of data will make it difficult to explain intra-month variations as well.

- The changing nature of the number of weeks belonging to a month makes it difficult to identify the fluctuations within a month.

- Countries almost universally follow the Gregorian calendar. Sri Lanka too follows the same calendar to set its weekends and all statistics are compiled according to this calendar. However, holidays do not follow the Gregorian calendar, as they are based on the festivals and religious observances of different ethnic groups in the country, which do not necessarily follow the pattern of the Gregorian calendar. This makes it difficult to model high frequency time series.

- Currency in circulation displays a pronounced seasonality, with weekly, monthly and annual patterns. The monthly pattern of the currency in circulation may be determined by the payment of salary advances or salaries. The amount of the currency in circulation may increase on the weekend and decline afterwards the trading day effect. Further, the amount of currency increases before the Sinhala/Tamil New Year, Vesak, Christmas and other national holidays.

Given these constraints, the paper attempts to identify the short term variations, as far as possible, in the currency in circulation in Sri Lanka. ${ }^{3}$ To model the currency in circulation it is important to know the factors which affect its movement, especially its trend and seasonality. Limitations in the data and the models specified will be discussed in Section 3 wherever appropriate.

The sample covers the period of 1 January 2000 to 31 August 2005, i.e., 2,070 days. The actual data for the period of 1 September 2005 to 30 November 2005 have been used to test the validity of the forecast. The daily data for currency in circulation compiled by the Central Bank are used for the analysis. On the basis that the currency in circulation on any Friday circulates in the economy during the weekend, all 365/366 days were included in the sample. ${ }^{4}$ In the case of holidays, data pertaining to the last working day is applied for the holiday.

3/ The model specification is based on the methodology developed in Diebold in [2004] 'Elements of Forecasting' for modelling and forecasting time series with high frequency.

4/ A five day week is considered at the initial level of estimation. It was found that data series with full calendar year perform well in all models. 


\section{B. Model Specification}

It is empirically obvious that in many economic time series a trend exists. A trend is defined as slow, long run, evolution in the variable. It is produced by slowly evolving factors such as preferences, technologies, institutions and demographics. Chart 1 shows daily data on currency in circulation in Sri Lanka from 1 January 2000 to 31 October 2005, in which the trend appears roughly linear.

That is, a simple liner function of time provides a description of the trend. The variable TIME is constructed artificially and is called time trend or time dummy.

$$
\mathrm{T}_{t}=\beta_{0}+\beta_{1} \mathrm{TIME}_{t}
$$

Where sample size is $n$ and TIME $=(1,2,3, \ldots \ldots \ldots \ldots . . . n-1, n)$

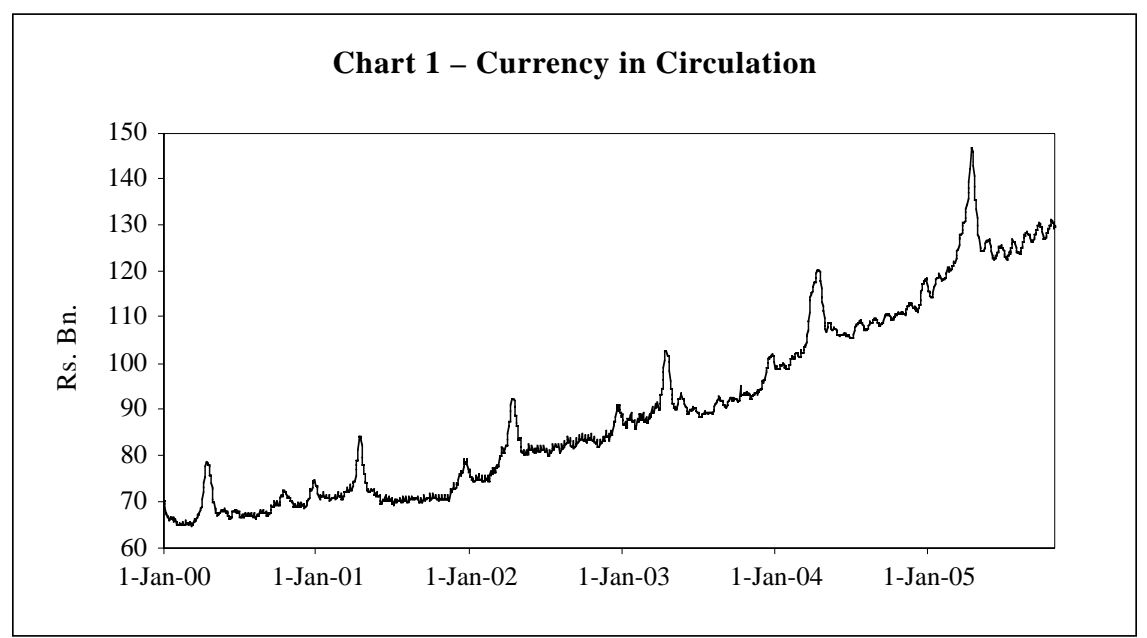

Sometimes, the trend appears nonlinear, or curved, for example, when a variable increases at an increasing or decreasing rate. A quadratic trend model can capture the nonlinearities.

$$
\mathrm{T}_{t}=\beta_{0}+\beta_{1} \mathrm{TIME}_{t}+\mathrm{TIME}_{t}^{2}
$$

Even though the quadratic trend fits better than the linear trend, it is appropriate to test other types of trend models as well. If the trend is characterized by a constant growth at rate $\beta_{1}$, then the equation is 
$\mathrm{T}_{t}=\beta_{0} \mathrm{e}^{\text {B1TIME }}$

In logarithmic form

$\operatorname{In}\left(\mathrm{T}_{t}\right)=\operatorname{In}\left(\beta_{0}\right)+\beta_{1} \mathrm{TIME}_{t}$

Or a quadratic trend regression in logarithmic form

$\operatorname{In}\left(T_{t}\right)=\operatorname{In}\left(\beta_{0}\right)+\beta_{1} \operatorname{TIME}_{t}+\beta_{2} \operatorname{TIME}_{t}^{2}$

Most model selection criteria attempt to find the model with the smallest out-of-sample 1-step ahead mean squared prediction error. Selecting the model with the smallest mean squared error (MSE) is equivalent to selecting the model that maximizes $\mathrm{R}^{2}$ In sample MSE cannot rise when more variables are added to the model, and typically, it will fall continuously as more variables are added. However, including more variables in the model would not necessarily improve its out of sample forecasting performance, although it will improve the model's fit on historical data. To reduce the bias associated with MSE and related indicators, it is necessary to penalize the in sample residual variance for degrees of freedom. Two very important such criteria are the Akaike Information Criterion (AIC) and the Schwarz Information Criterion (SIC). The model with the lowest AIC and SIC is considered as the best fit to the data.

Seasonality persists in many economic time series. Chart 1 shows clear seasonal peaks in April each year, associated with the Sinhala/Tamil New Year festival. There may also be seasonality intra month or intra week due to spending habits, salary payments etc., as mentioned earlier. One way to deal with seasonality in a series is simply to remove it and then to model and forecast the seasonally adjusted series. This strategy is often appropriate in economic forecasting where interest typically centres on identifying all the variations in the series. However, if seasonality is responsible for a larger part of the variation in a particular data series, it is important to model with unadjusted data series.

A commonly used technique for modeling seasonality is regression on seasonal dummies. In many countries, four seasons are commonly used. However, in the case of Sri Lanka where four seasons are not visible, such climatic impact on currency in circulation is not expected. If dealing with monthly data 12 seasons can be observed. In the case of weekly data 52 seasons can be identified. Since currency in circulation with daily observations is available, within week and within month variations can be examined. 
The seasonal dummy model is

$$
\mathrm{Y}_{t}=\sum_{i=1}^{\mathrm{s}} \gamma_{i} \mathrm{D}_{i t}+\varepsilon_{t}
$$

Where $s$ is the number of seasons considered.

Inclusion of a full set of seasonal dummies and an intercept produces perfect multicollinearity, and therefore, the intercept is excluded from the model. In the absence of seasonality $\gamma_{i} s$ are all the same and we can drop the seasonal dummies and include an intercept.

Since the data series exhibits a trend, the model takes the form

$$
\mathrm{Y}_{t}=\beta_{1} \mathrm{TIME}_{t}+\sum_{i=1}^{\mathrm{s}} \gamma_{i} \mathrm{D}_{i t}+\varepsilon_{t}
$$

The standard seasonality represents general calendar effects. Two additional important calendar effects are holiday variations and trading day variations.

Holiday variations refer to the fact that the dates of some holidays change over time. That is, although the holiday occurs at approximately the same month each year, the exact date changes. Some examples are the monthly poya holiday, Sinhala/Tamil New Year, Vesak, Deepavali and Easter. The behaviour of the currency in circulation depends, in part, on the timing of such holidays. Therefore, it is important to keep track of them in a forecasting model. As with seasonality, holiday effects may be handled with dummy variables. In addition to seasonal dummies, a dummy variable can be introduced to reflect the effect of special holidays, which would be 1 for holidays and 0 otherwise.

As the number of trading days in a particular month or week may have a higher impact on the currency in circulation, in all models the trading day effect too is examined alternatively for holiday variable. In the monthly model, the number of trading days in that month is the value of this variable. In the daily series, all trading days are indicated as 1 and 0 otherwise. Festival season variation refers to the fact that certain months contain festivals which are important considerations for modeling and forecasting currency in circulation. Therefore, a variable is included in the weekly and daily models to capture the effect of different festival seasons. However, in a monthly model, the effect of the festival could not be isolated from the seasonal factors. 
Furthermore, especial events, such as elections might have positive impact on the currency in circulation as the public demand more currency due to uncertainty associated with the election.

The complete model is

$$
\mathrm{Y}_{t}=\beta_{1} \mathrm{TIME}_{t}+\sum_{i=1}^{\mathrm{s}} \gamma_{i} \mathrm{D}_{i t}+\sum_{i=1}^{\mathrm{v}} \delta_{i} \mathrm{HD}_{\mathrm{HDV}}+\sum_{i=1}^{\mathrm{u}} \theta_{i}^{\mathrm{FS}} \mathrm{HDV}_{i t}+\varepsilon_{t} \ldots \ldots
$$

Where HDVs are the relevant holiday variables (number of variables is $v$ ) and FSVs are relevant festival season variables (the number of variables is $u$; in most cases $u=1$ ).

It is also important to develop the model to capture any cyclical pattern that may persist in the series, some way in which the present is linked to the past and the future linked to the present. However, this is more difficult than modeling trend or seasonality. First it is necessary to see whether the underlying probabilistic structure of the series is changing over time. If so, there would be no way to predict the future accurately on the basis of the past, as the laws governing the future would differ from those governing the past. Therefore, it is necessary to have its mean and covariance structure stable over time, i.e., the series needs to be covariance stationary. It is true that many economic variables are not covariance stationary. Even in the case of currency in circulation, there exists an upward trend, which corresponds to the $\gamma_{i}$ steadily increasing mean, and seasonality, which corresponds to means that vary with the season, both of which violate covariance stationarity. However, it is possible to achieve covariance stationarity with models that give special treatment to such non stationary components such as trend and seasonality, so that the cyclical component left over is likely to be covariance stationary. The right model for any covariance stationary series is some infinite distributed lag of white noise, called the Wold representation, which takes the form

$$
\begin{aligned}
& \mathrm{Y}_{t}=\mathrm{B}(\mathrm{L}) \varepsilon_{t}=\sum_{i=0}^{\mathrm{s}} \delta_{i} \mathrm{~b}_{i} \varepsilon_{t-1} \quad \text { where } \varepsilon_{t} \sim \mathrm{WN}\left(0, \sigma^{2}\right) \\
& \mathrm{b}_{0}=1 \text { and } \sum_{\mathrm{i}=0} \mathrm{~b}^{2}{ }_{i}<
\end{aligned}
$$


Therefore, after selecting an appropriate model to identify the dynamics operating in the currency in circulation series, correlogram analysis ${ }^{5}$ is carried out. Based on the findings, an autoregressive (AR), moving averages (MA) or autoregressive moving averages (ARMA) model is specified. Model selection procedure is discussed in Section 4 , together with estimation results.

The tool used in this analysis to model and forecast trend seasonality and cycles is one that regresses on a trend and seasonal dummies to capture the impact of trend and seasonality, and then captures the cyclical dynamics by allowing for ARMA effects in regression disturbances. The full model is

$$
\begin{aligned}
& \mathrm{Y}_{t}=\mathrm{T}_{t}(\theta)+\sum \gamma_{i} \mathrm{D}_{i t}+\sum \delta_{i} \mathrm{HD}_{\mathrm{HDV}}+\sum \theta_{i}{ }^{\mathrm{FS}} \mathrm{FSV}_{i t}+\varepsilon_{t} \\
& \Phi(\mathrm{L}) \varepsilon_{t}=\Theta(\mathrm{L}) \mathrm{V}_{t} \\
& \Theta(\mathrm{L})=1+\theta_{i} \mathrm{~L}+\ldots \ldots \ldots \theta_{q} \mathrm{~L}_{q} \\
& \Phi(\mathrm{L})=1+\varphi_{i} \mathrm{~L}+\ldots \ldots \ldots-\varphi_{q} \mathrm{~L}_{q} \\
& \mathrm{~V}_{t} \sim \mathrm{WN}\left(0, \sigma^{2}\right)
\end{aligned}
$$

$\mathrm{T}_{t}(\theta)$ is a trend, with underlying parameters $\theta$. For examples a linear trend has $\theta=\beta_{1}$ and $\mathrm{T}_{t}(\theta)=\beta_{1} \mathrm{TIME}_{t}$, while a quadratic trend has $\theta=\left(\beta_{1}, \beta_{2}\right)$ and $\mathrm{T}_{t}(\theta)=\beta_{1} \mathrm{TIME}_{t}+\beta_{1} \mathrm{TIME}_{t}^{2}$

In this equation, the trend, seasonal, holiday/ trading day variables, festival seasons, elections and harvest seasons are included. The disturbance follow an ARMA(p,q) process, of which pure auto regressions and moving averages are special cases. In any particular application, as discussed in Section 4, various trend effects, seasonal and other calendar effects and ARMA cyclical effects may not be required and could be dropped. When seasonal dummies are insignificant and dropped, an intercept could be included.

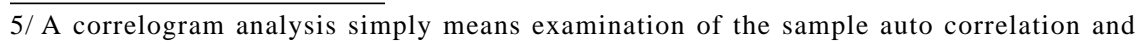
partial auto correlation functions (with two standard error bands), together with related diagnostics, such as Q statistics. 


\section{Estimation - Results}

\section{A. Estimation with Monthly Data}

The entire study covers the period 1 January 2000 to 31 December 2005 with daily data on currency in circulation. However, in the case of forecasting liquidity in the system for a long time horizon, it is more important to have a monthly forecast than a weekly or a daily forecast. Using a daily or a weekly forecast for long time horizons tends to produce larger errors in longer-term estimates. Therefore, in order to identify inter month variations and estimate monthly requirements of currency for monitoring monetary targets and planning for liquidity management one or two months ahead, it was decided to examine the behaviour of currency in circulation on a monthly basis. Data on Monthly averages of currency in circulation are used for the estimates.

A simple liner function of time, Equation 1, provides a description of the trend. The variable TIME is constructed artificially and is called the time trend or time dummy.

$$
\text { CURRENCY }_{t}=59764+816.0147 \mathrm{TIME}_{t}
$$

$$
\text { (49.4765) (23.6939) }
$$

Where sample size is 60 and TIME $=(1,2,3, \ldots \ldots \ldots .60)$

Chart 2.1, which depicts currency in circulation, the fitted trend and residuals, shows a somewhat adequate representation. However, a deviation of actual currency in circulation from the trend is apparent.

Therefore, a quadratic trend model is used to capture the nonlinearities observed in the currency in circulation.

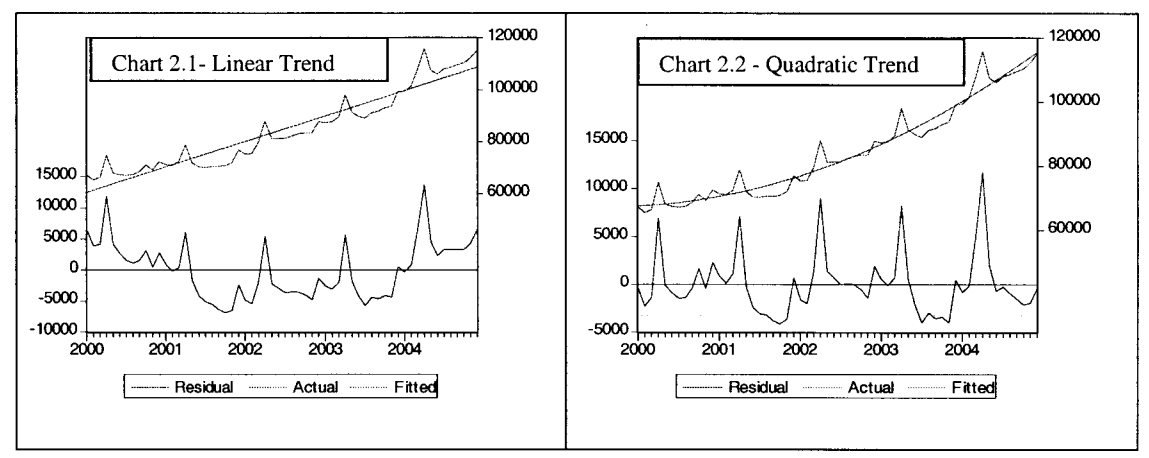


CURRENCY $_{t}=67374+79.5716 \mathrm{TIME}_{t}+12.0728 \mathrm{TIME}_{t}^{2}$

Chart 2.2 presents the currency in circulation data with a superimposed quadratic trend. Although the quadratic trend fits better than the linear trend, it is still appropriate to test other types of trend models as well.

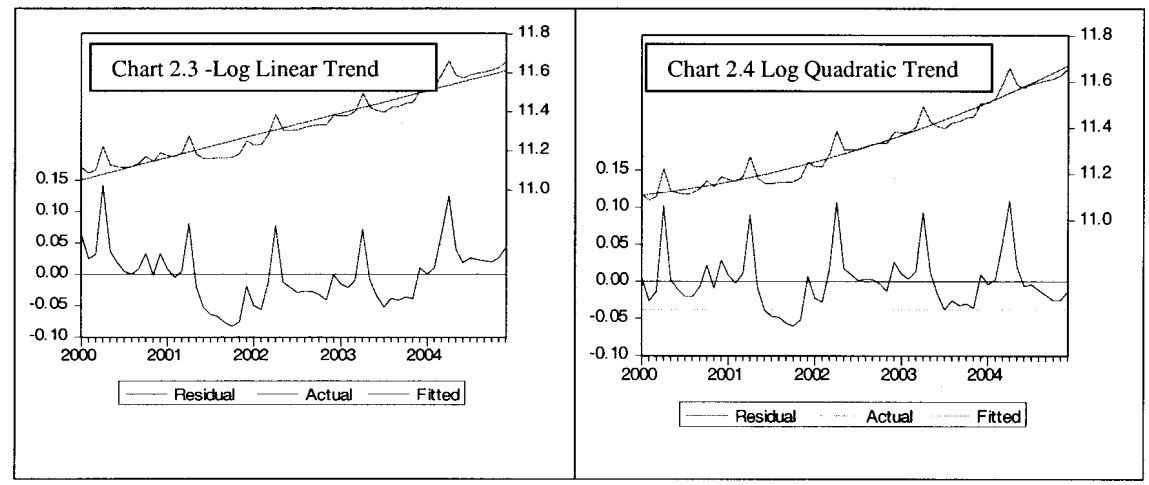

In Chart 2.3, which shows the logarithm of currency in circulation, the trend appears to be approximately linear. In this data series, the trend appears to be non linear in levels but linear in logarithms, that is, it has a log linear trend. If the trend is characterized by constant growth at rate $\beta_{1}$, then the equation is

$$
\mathrm{T}_{t}=\beta_{0} \mathrm{e}^{\beta 1 \mathrm{TIME}}
$$

In logarithmic form

$$
\log \left(\text { CURRENCY }_{t}\right)=11.0424+0.0095 \mathrm{TIME}_{t}
$$

$$
\text { (900.5412) (27.1168) }
$$

$$
\begin{gathered}
\text { LCURRENCY }=11.1057+0.0033 * \text { TIME }+0.0001 * \text { TIME2 } \\
(722.3511) \quad(2.8786)
\end{gathered}
$$

$$
\mathrm{R}^{2}=0.9502 \mathrm{AIC}=-3.6338 \mathrm{SCI}=-3.5290 \mathrm{DW}=1.2180
$$

Based on the selection criteria discussed in Section 2, the above results suggest that the log linear and quadratic trend model in logs fits the data well, 
Table 1 - Results of Trend Models

\begin{tabular}{|l|c|c|c|c|}
\hline \multicolumn{1}{|c|}{ Model } & $\begin{array}{c}\text { Within } \\
\text { sample MSE }\end{array}$ & Adj. R & AIC & SIC \\
\hline Linear & 20666667 & 0.9047 & 19.7469 & 19.8167 \\
Quadratic Trend & 10150000 & 0.9523 & 19.0714 & 19.1759 \\
Log Linear & 0.002126 & 0.9269 & -3.2489 & -3.1791 \\
Log Quadratic Trend & 0.001399 & 0.9502 & -3.6338 & -3.5290 \\
\hline
\end{tabular}

but that the quadratic trend model performs slightly better in both within the sample and out of sample forecasts. As shown in Chart 2.4 and estimation results given in Equation 3.4, currency in circulation trends upward and the trend appears nonlinear in spite of the fact that logarithms are used. The residual plot shows that the fitted trend increases at a decreasing rate and both the linear and quadratic terms are significant. The adjusted $\mathrm{R}^{2}$ is 95 per cent, reflecting the fact that the trend is responsible for a large part of the variation in the currency in circulation. The residual plot shows obvious residual seasonality and Durbin-Watson statistics suggests serial correlation in errors. The residual plot also suggests that there may be a cycle in residuals, although it is difficult to establish a clear case as the pervasive seasonality swamps the picture and make it difficult to infer much.

The residual correlogram and its graph confirm the importance of the seasonality. The residual sample auto correlation function has large spikes, far exceeding the confidence levels, at the seasonal displacements, 12, 24 and

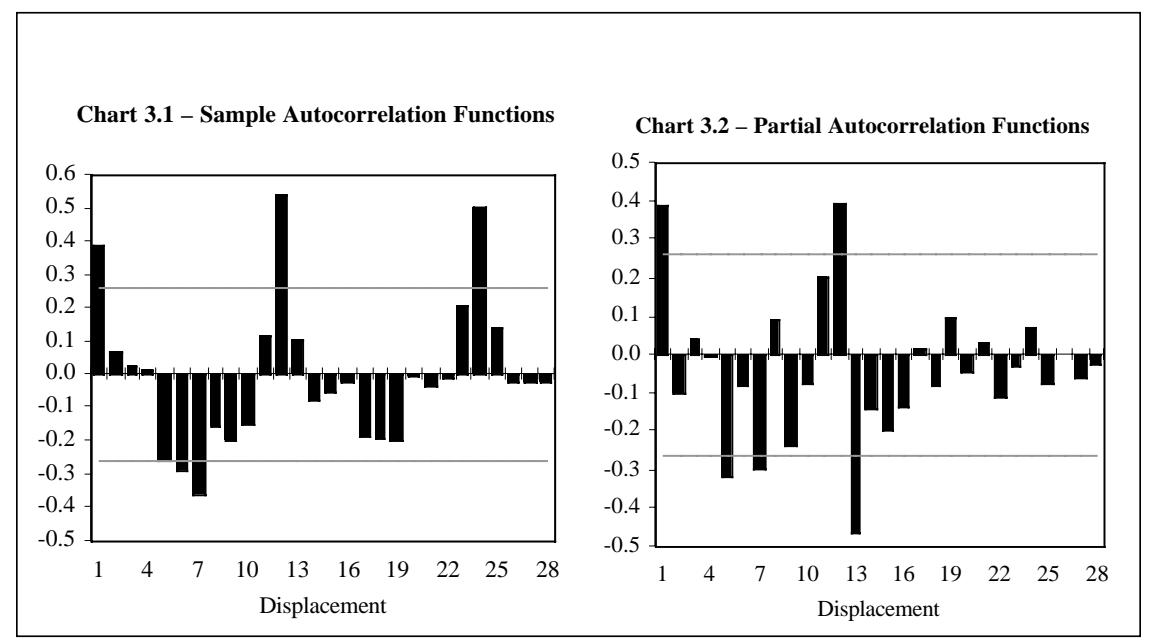


36. It indicates some cyclical dynamics as well. Apart from the seasonal spikes, the residual sample auto correlation and partial auto correlation function oscillate, and the Ljung-Box statistic rejects the white noise null hypothesis even at very small, non seasonal displacements.

$$
\begin{aligned}
& \text { LCURRENCY }=0.0034 * \text { TIME }+0.0001 * \text { TIME } 2+11.0989 * \mathrm{D} 1 \\
& \text { (6.0231) } \\
& \text { (11.2575) } \\
& \text { (963.6170) }
\end{aligned}
$$

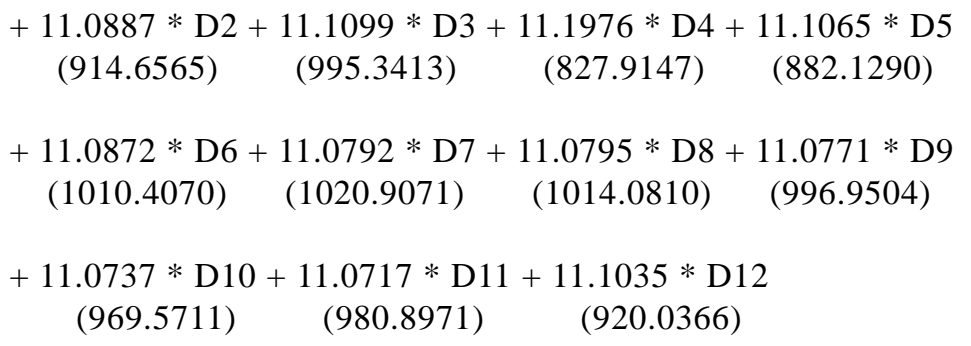

$$
\begin{aligned}
& +0.0308 * \text { ELECTION }+0.0013 * \text { HOLI } \\
& \text { (2.6042) (0.4668) }
\end{aligned}
$$

$$
\mathrm{R}^{2}=0.9915 \quad \mathrm{AIC}=-4.9408 \quad \mathrm{SCI}=-4.3823 \quad \mathrm{DW}=0.3423
$$

Where,

$$
\begin{array}{ll}
\text { LCURRENCYD } & =\text { Log of Currency in Circulation }\left(1^{\text {st }} \text { difference }\right) \\
\text { HOLI } & =\text { Number of holidays per month, } \\
\text { ELECTION } & =1 \text { for the month having election, } 0 \text { otherwise } \\
\text { TIME }_{t} & =t=1,2, n-1, n(n=60) \\
\text { D1, D2.....D12 } & =\text { Seasonal factors for January, February...December }
\end{array}
$$

Equation 3.5 shows the results of regression on quadratic trend and a full set of seasonal dummies. The quadratic trend remains highly significant. The adjusted $\mathrm{R}^{2}$ rises to almost 100 per cent and the standard error of the regression falls to 0.0183 . The residual plot shows no seasonality as it is now captured by the model, but it confirms the signal given by the Durbin - Watson statistic of serial correlation. The residual correlograms in Chart 4.1 and Chart 4.2 show that the partial auto correlations oscillate and decay slowly and they exceed the Bartlett standard errors frequently. The Ljung-Box test strongly rejects the white noise null at all displacements. The residual sample auto correlations cut off at displacement 1 . All of these factors suggest that an AR (1) would provide a good approximation to the disturbance's Wold representation. 


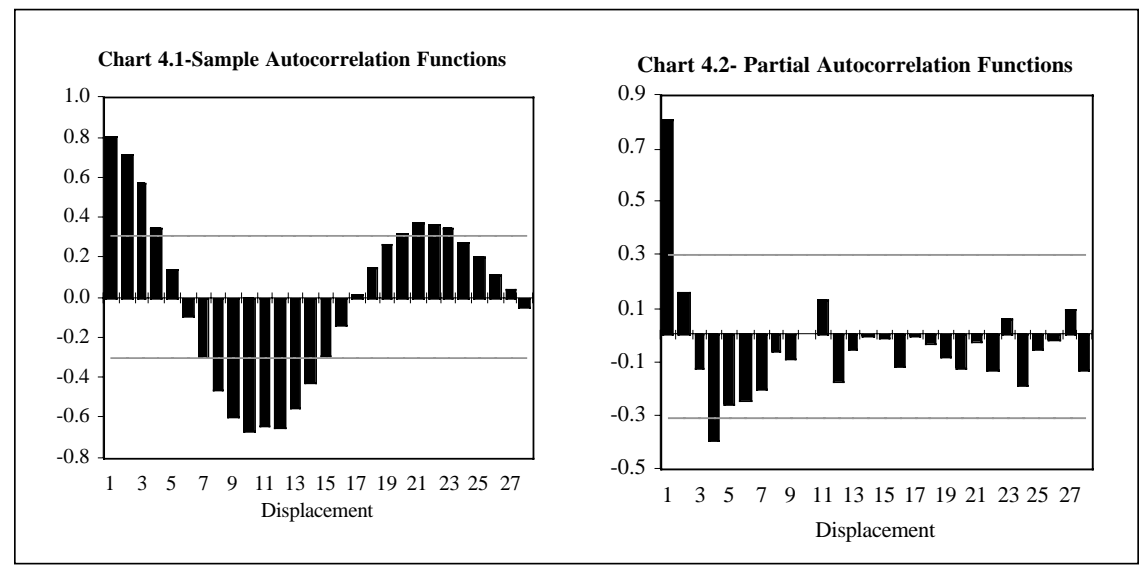

A model with a quadratic trend, seasonal dummies and AR(1) improved the R2 to 99.7 per cent and Durbin-Watson statistic confirms that it is free of serial correlation. The standard error of the regression is as small as 0.01 . The residual plot in Chart 5 reveals no pattern and looks like white noise. The residual sample auto correlations and partial auto correlations display no patterns, and are mostly inside the Bartlett bands. The Ljung-Box statistics are also good for small and moderate displacements. The histogram and normality test applied to the test suggest that the residuals appear to be fairly well approximated by a normal distribution.

$$
\begin{aligned}
& \text { LCURRENCY }=0.0059 * \text { TIME }+6.6887 \mathrm{e}-05 * \mathrm{TIME} 2+11.0529 * \mathrm{D} 1 \\
& \text { (2.8332) (2.6071) (189.5149) } \\
& \begin{array}{c}
+11.0437 * \mathrm{D} 2+11.0676 * \mathrm{D} 3+11.1540 * \mathrm{D} 4+11.0641 * \mathrm{D} 5 \\
(189.3883) \quad(190.2798) \\
(191.2944)
\end{array} \\
& +11.0467 * \mathrm{D} 6+11.0399 * \mathrm{D} 7+11.0404 * \mathrm{D} 8+11.0381 * \mathrm{D} 9 \\
& \begin{array}{lll}
(190.3868) \quad(190.5530) \quad(190.6454) \quad(190.6933)
\end{array} \\
& \begin{array}{c}
11.0358 * \mathrm{D} 10+11.0334 * \mathrm{D} 11+11.0655 * \mathrm{D} 12+0.00213 * \text { HOLIDAY } \\
(190.8448) \\
(190.9925)
\end{array} \\
& +0.0277 * \text { ELECTION }[\mathrm{AR}(1)=0.8541] \\
& \text { (5.5660) (10.0667) } \\
& \mathrm{R}^{2}=0.9975 \quad \mathrm{AIC}=-6.1191 \quad \mathrm{SCI}=-5.5201 \quad \mathrm{DW}=1.8669
\end{aligned}
$$




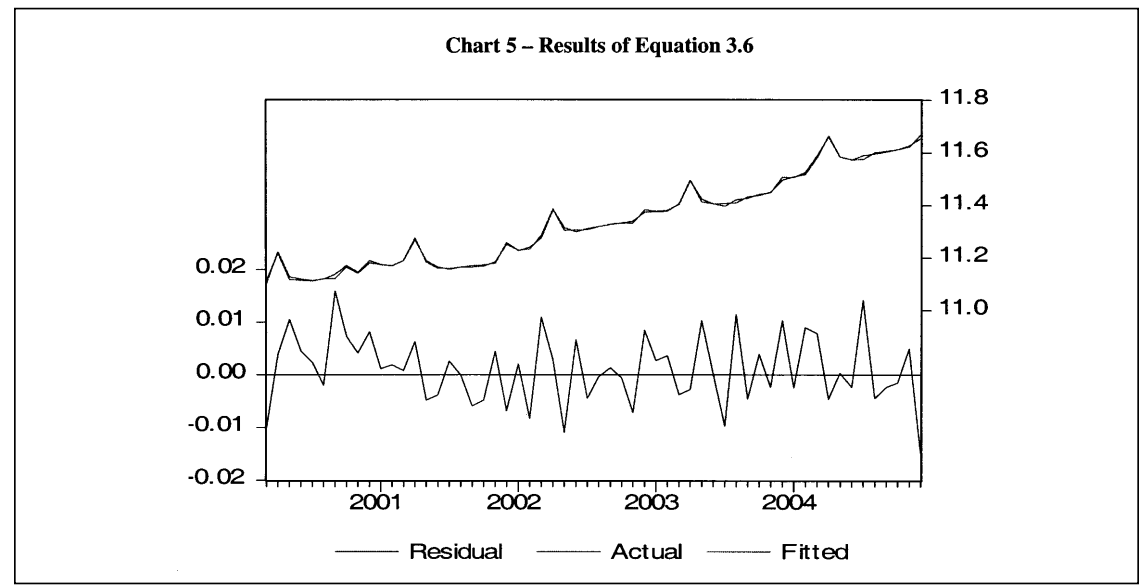

For the purpose of analyzing the economic implications (Section 4) and to measure the monthly changes of currency in circulation, the model is re-estimated with first differences of the data. To estimate the effect of each month of the year separately, and to avoid the dummy variable trap, in the empirical specification the regression has done without a constant term. The monthly effect has been captured by the $\mathrm{D} j(\mathrm{~J}=1,2,3,4, \ldots .11,12$ ) respectively. In the empirical specification, same variables included in Model 3.6 have been added to capture the effect of bank holidays, elections etc.

The regression results reported below find evidence in favour of the earlier findings for monthly data. More importantly, the results reveal that

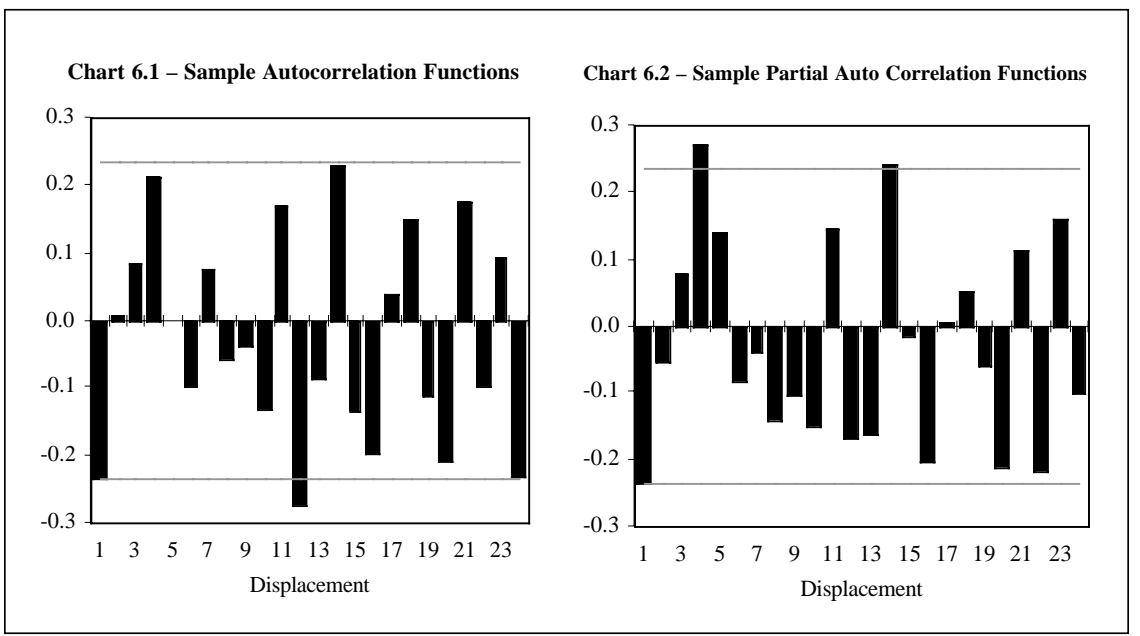




\section{Chart 7 - Results of Equation 3.7}

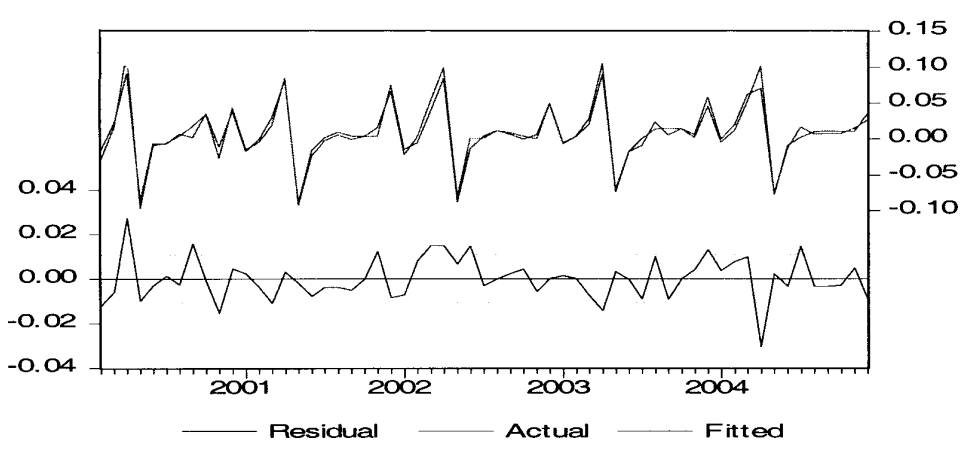

there is a pronounced month of the year effect in the growth rates of currency in circulation. Chart 9 presents the graph of estimated $\mathrm{D} j$ as a function of $j(1,2,3, \ldots .11,12)$.

LCURRENCYD $=0.0002 *$ TIME $-0.0311 * \mathrm{D} 1-0.0216 * \mathrm{D} 2+0.0156 * \mathrm{D} 3$

$$
\begin{array}{llll}
(2.1988) & (-4.251544) \quad(-3.1405) \quad(2.6010)
\end{array}
$$

$$
\begin{gathered}
+0.0674 * \mathrm{D} 4-0.1050 * \mathrm{D} 5-0.0248 * \mathrm{D} 6-0.0075 * \mathrm{D} 7 \\
(8.5818) \quad(-14.6352) \quad(-4.2793)
\end{gathered}
$$$$
-7.9672 \mathrm{e}-05 * \mathrm{D} 8-0.0052 * \mathrm{D} 9-0.0061 * \mathrm{D} 10-0.0124 * \mathrm{D} 11
$$$$
\begin{array}{llll}
(-0.0140) & (-0.8749) \quad(-0.9972) & (-2.0291)
\end{array}
$$

Chart 8.1 - Sample Autocorrelation Functions

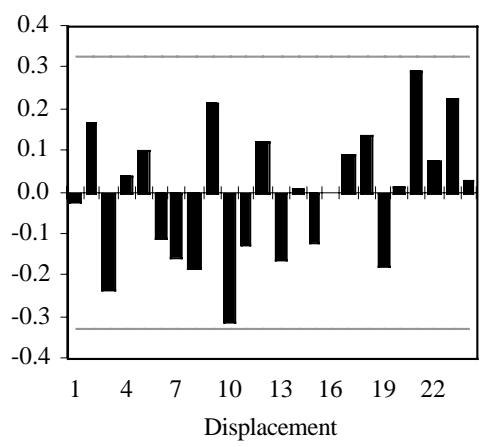

Chart 8.2 - Sample Partial Autocorrelation Functions

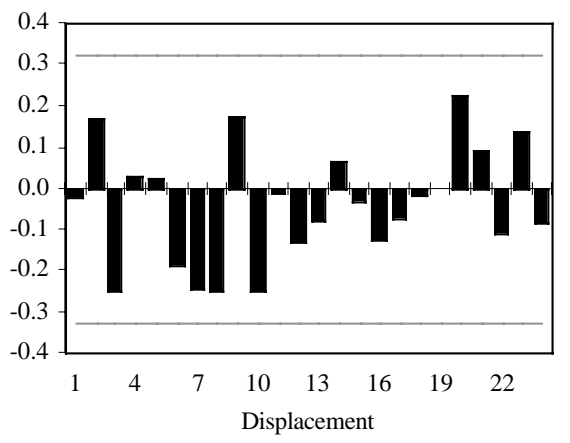




$$
\begin{gathered}
+\underset{(3.6640)}{0.0248 * \mathrm{D} 12+0.0061 * \mathrm{HOLI}+}+\underset{(3.5917)}{0.0280} * \text { ELECTION } \\
\mathrm{R}^{2}=0.9950 \quad \mathrm{AIC}=-6.1004 \quad \mathrm{SCI}=-5.4759 \quad \mathrm{DW}=2.1210
\end{gathered}
$$

The model produced white noise residuals. The residual sample autocorrelations and partial auto correlations display no patterns and are mostly inside the confidence bands, while the histogram and normality test too performed well. 6

The model clearly indicates significant positive seasonality in all months except August, September and October The coefficients are positive and relatively higher in April and December. Chart 9, which plotted the coefficients of seasonal dummies, confirms that clear positive seasonality is

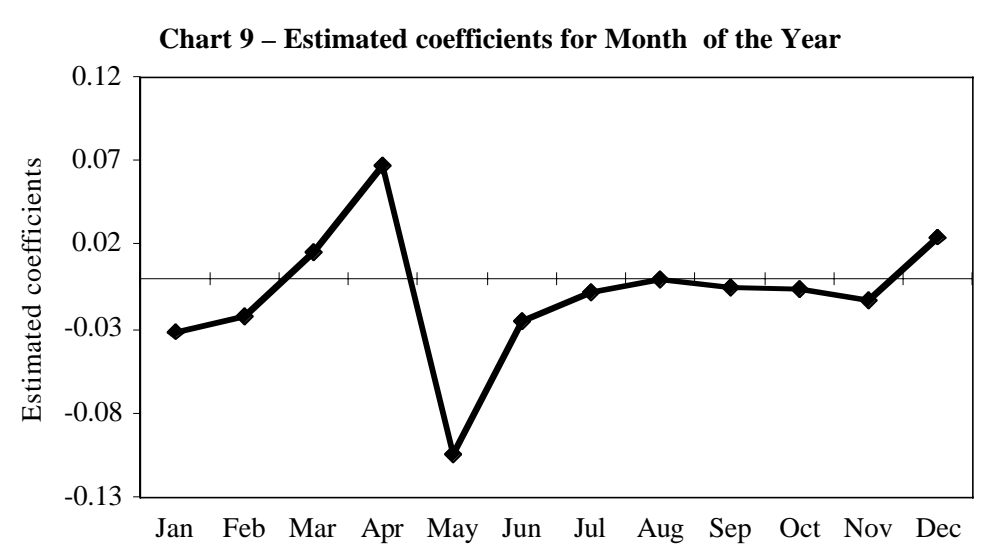

6/ To select the model that produces an accurate estimate of the 1-step-ahead out of sample prediction error variance, it is necessary to penalize the in sample residual variance (the MSE) reflecting the degrees of freedom used. The model that minimizes the standard error of the regression or the model that maximizes adjusted $\mathrm{R}^{2}$, are equivalent, and they do penalize for degrees of freedom used. Two very important such criteria currently used in the literature are Akaike Information Criterion (AIC) and the Schwarz Information Criterion (SIC). Comparing the properties of all these criteria, recent literature suggests that MSE is inconsistent because it doesn't penalize for degrees of freedom. $S^{2}$ penalizes [What is S2 please] for degrees of freedom but not enough to use as a consistent model selection procedure. The AIC penalizes degrees of freedom more heavily than $\mathrm{S}^{2}$, but SIC, which penalizes degrees of freedom most heavily, is consistent than $S^{2}$ and AIC. The AIC, although inconsistent, is asymptotically efficient, whereas SIC is not. Therefore, the literature suggests examining both AIC and SIC as model selecting criteria, although on many occasions they select the same model by producing minimum values. If these two criteria select different models, the use of the model selected by SIC is recommended. 
exhibited in April and December. Within the year, monthly demand tends to increase gradually from March. This was due to the Sinhala/Tamil New Year festival, which occurs on the 13 and 14 of April each year. This growth may also be partly attributable to the Maha harvesting season which coincides with the New Year. However, it is not possible to distinguish the harvesting effect from seasonality in the monthly model, although it may be possible with weekly and daily data. Currency growth thus peaks in April and then starts to fall in May. The seasonality smoothes off during June-November and then increase in December due to the Christmas demand. The demand starts falling in January and picks up in March. Within the month variations will be discussed in Section 3.3 below. The holiday effect and the variable which represents elections were found to be significant. The impact of the Sinhala/Tamil New Year and Christmas are captured by the seasonal dummies for April and December.

Forecast Based on Monthly Data

\begin{tabular}{|c|c|c|c|c|c|c|}
\hline & \multicolumn{3}{|c|}{ Rs. Billion } & \multirow{2}{*}{ As a $\%$} & & \multirow{2}{*}{$\begin{array}{c}\text { Forecast } \\
\text { (Rs. Billion) }\end{array}$} \\
\hline & Actual & Forecast & Difference & & & \\
\hline 2005 & & & 2006 & & & \\
\hline January & 117.0 & 116.6 & -0.4 & -0.3 & January & 133.4 \\
\hline February & 119.5 & 117.1 & -2.4 & -2.0 & February & 132.4 \\
\hline March & 127.0 & 122.8 & -4.2 & -3.3 & March & 137.2 \\
\hline April & 137.5 & 135.8 & -1.7 & -1.2 & April & 151.5 \\
\hline May & 125.3 & 124.1 & -1.2 & -0.9 & May & 140.1 \\
\hline June & 124.0 & 123.9 & -0.1 & -0.1 & June & 138.6 \\
\hline July & 124.6 & 124.6 & 0.1 & 0.1 & July & 140.4 \\
\hline August & 126.4 & 127.0 & 0.6 & 0.5 & August & 143.4 \\
\hline September & 128.4 & 127.9 & -0.4 & -0.3 & September & 145.7 \\
\hline October & 129.4 & 129.6 & 0.2 & 0.2 & October & 147.9 \\
\hline November & 131.8 & 132.1 & 0.3 & 0.2 & November & 148.3 \\
\hline December & 134.3 & 134.2 & -0.1 & -0.1 & December & 154.4 \\
\hline $\begin{array}{c}\text { SER (within } \\
\text { sample) (a) }\end{array}$ & & & 1.0108 & & & \\
\hline $\begin{array}{l}\text { Out of } \\
\text { sample } \\
\text { forecast error }\end{array}$ & & & & & & $1.5424(b)$ \\
\hline
\end{tabular}

(a) Standard Error of Regression (SER) (in Rs.Bn.) $=\left[\mathrm{S}\right.$ (Actual-Forecast) ${ }^{2} /$ Degrees of Freedom]

(b) This model under estimated reserve money in February, March and April 2005 due to un-expected impact of Tsunami related movements in currency. 


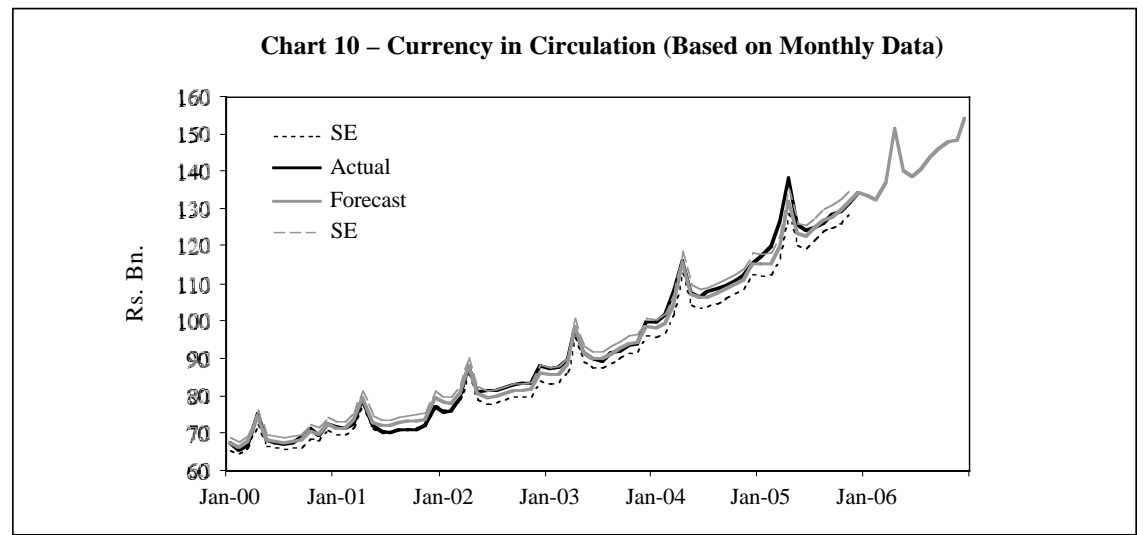

The estimated model is used to forecast historical data on currency in circulation and 12 month-ahead extrapolation forecasts for January - December 2006. Actual data for January - October 2005 were used for post sample validity tests. The forecast appears reasonable. It is visually apparent that the model has the ability to pick up the seasonal patterns that dominate the local behaviour of the series. Chart 10 shows actual historical data, the forecast and the January - September 2005 realization.

The estimate seems reasonable as it closely capture the trend and the seasonal and cyclical patterns in the past, and performs very well in post sample validity tests. During this period, forecast errors in many months were less than 1 per cent and post sample estimation error is less than 2 per cent. Chart 10 which shows changes in currency in circulation over the previous month, shows the monthly estimates for January - December 2006 following a similar pattern shown during 2001-2005. Therefore, the estimates may productively be used as a basic input in long term liquidity assessment.

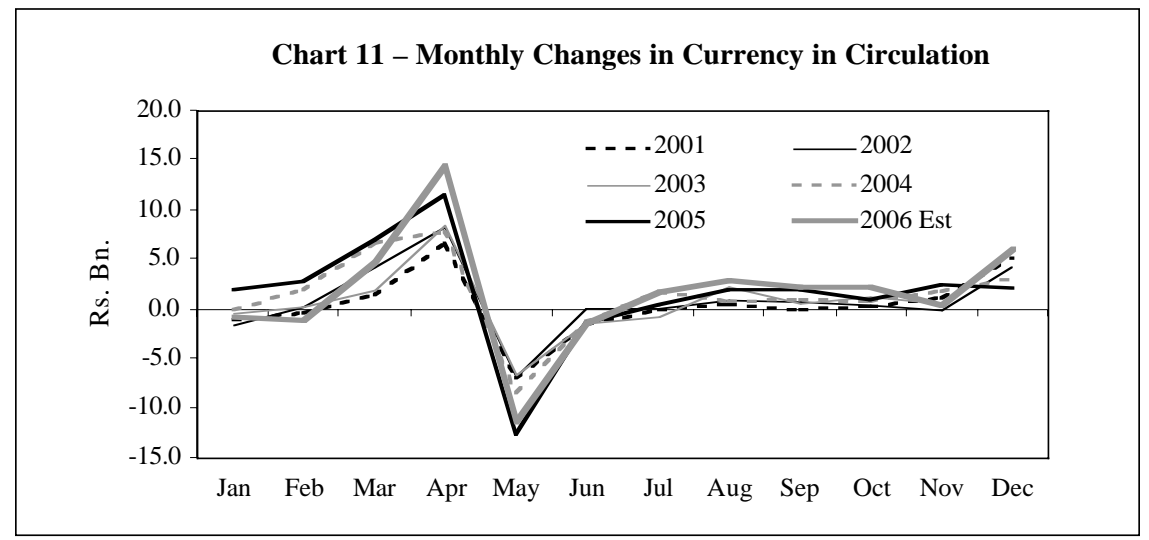




\section{B. Estimation with Weekly Data}

Data on currency in circulation are compiled by the CBSL on daily basis. Data from Monday to Friday are averaged to obtain a weekly series of currency in circulation. Chart 12 shows the weekly movements of currency in circulation from 03 January 2000 to 2 September 2005, i.e., 296 weeks. Eight weeks up October 2005 were used for post sample testing of the forecast.

Chart 12 shows clear evidence of a trend in the weekly average of currency in circulation. Using the same methodology developed in Section 3.1 it was found that quadratic trend model in logarithmic form fits data well.

Chart 12 also clearly indicates intra month seasonality in some months (April and December). However, seasonality is not that evident in other months. Therefore, to examine the intra- month seasonality more intensively, the year over year line graphs of currency in circulation are examined. Chart 12 reveals that for all the years, the patterns are very similar, indicating no evidence of a structural break or change in seasonality during the period. The minor variations from year to year occur mostly due to $(a)$ shift of the week and (b) festivals which do not strictly follow the Gregorian calendar. In order to examine intra-month seasonality in a systematic manner, seasonal dummies were included in the model. To represent the $5^{\text {th }}$ week in some months, a $5^{\text {th }}$ dummy variable was also included.

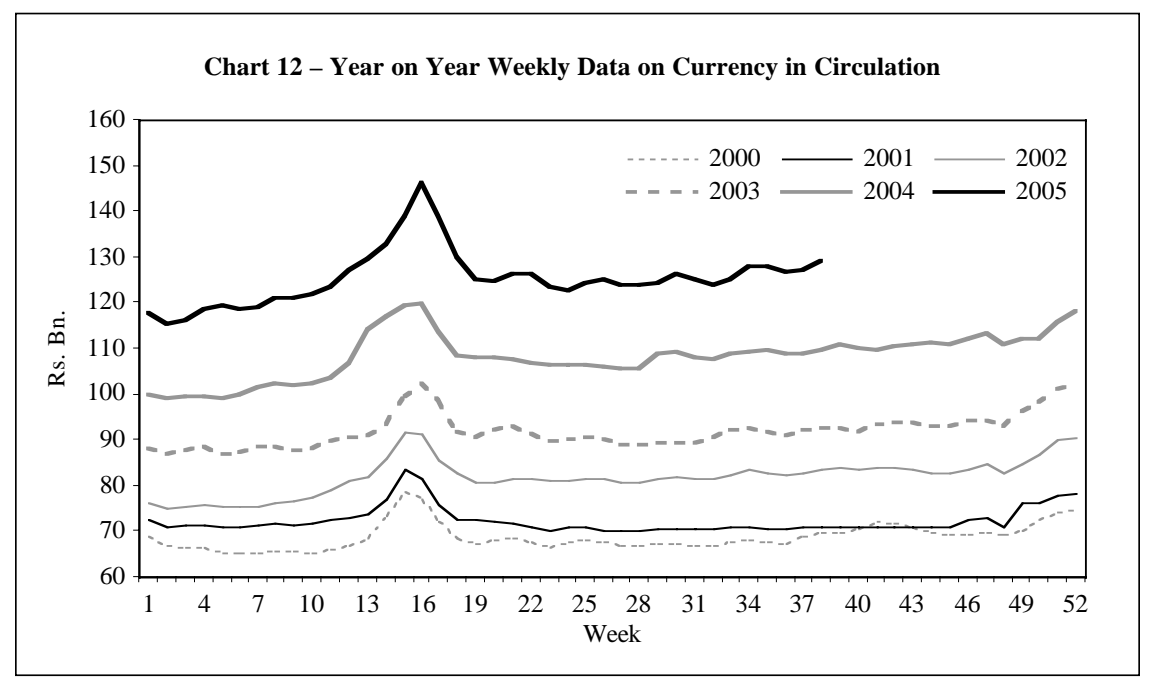




$$
\begin{aligned}
& \text { LCURRENCY }=0.0025 * \text { TIME }+10.9834 * \mathrm{D} 1+10.9850 * \mathrm{D} 2 \\
& \text { (15.5489) (359.8467) (359.9390) } \\
& \begin{array}{c}
+10.9932 * \mathrm{D} 3+10.9917 * \mathrm{D} 4+10.9847 * \mathrm{D} 5+0.01258 * \text { CHRIST } \\
(360.2060) \\
(360.0916)
\end{array} \\
& +0.0408 * \text { NEWYEAR }+0.0017 * \text { HOLIDAY + } 0.0082 * \text { HARVEST } \\
& \text { (13.9584) (1.9740) (4.3525) } \\
& +0.0195 * \text { ELECTION }+[\text { AR }(1)=0.9382] \\
& \text { (3.2722) (50.8241) } \\
& \mathrm{R}^{2}=0.9957 \quad \mathrm{AIC}=-5.6683 \quad \mathrm{SCI}=-5.5184 \quad \mathrm{DW}=1.8889
\end{aligned}
$$

The model clearly identifies the significance of the New Year and Christmas seasons in changing demand for currency. In the monthly model, the impact of these two variables is captured by seasonal dummies. The impact of other public holidays was also found significant, but the coefficient is smaller than the coefficients for the New Year and Christmas. The elasticity estimated for the holiday effect in the monthly model is nearly 4 times bigger than the estimate in the weekly model. The elasticity for elections is almost double in the monthly model. Two dummy variables representing the impact of election weeks and two paddy harvesting seasons, Yala and Maha, too were found to be highly significant in this model. However, the effect of the variable for harvest could not be identified separately in the monthly model. All these factors show a positive impact on currency demand.

Chart 13, which presents estimated coefficients of seasonal dummies, indicates clear seasonality among weeks. Within each month, weekly currency

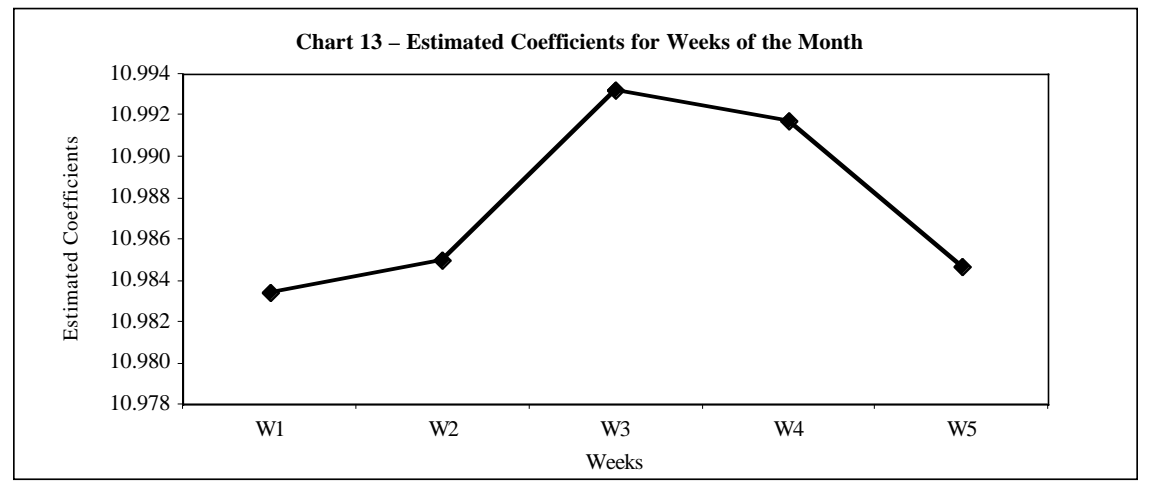


demand tends to increase during the second week and remains high in the third week and then tends to decline. However, the variations among the weeks are small in magnitude. Most of the payments to individuals are made during this time. The government pays salary advances to public school teachers and public servants around the $10^{\text {th }}$ of each month. Teachers' salaries are paid around the $20^{\text {th }}$ while salaries to other government employees, bank employees etc. are paid around the $25^{\text {th }}$ of each month. ${ }^{7}$ This payment mechanism is likely to create a pronounced 'day of the month' effect in currency in circulation. Within a month, seasonality among weeks varies from $0.001-0.01$, but this variation is quite high in April and December.

\section{Forecast Based on Weekly Data}

The model developed is used to estimate currency in circulation for past periods and to make 3 month-ahead extrapolation forecasts for January - March 2006. Actual data for 02 September 2005 - 27 January 2006 were used for a post sample validity test. The within sample and out of sample forecast errors were small, while other residual tests such as a Q test, normality test etc. suggest that the model fits the data well. Although, the forecast based on average weekly data cannot be compared directly with the forecast based on average monthly data as some weeks extend into the following month, this forecast provides reasonably similar values to these produced by the monthly model. ${ }^{8}$ It is visually apparent that the model has the ability to pick up seasonal patterns that dominate the local behaviour of the series. Chart 14 shows actual historical data, the forecast and the January 2005 - January 2006 realization.

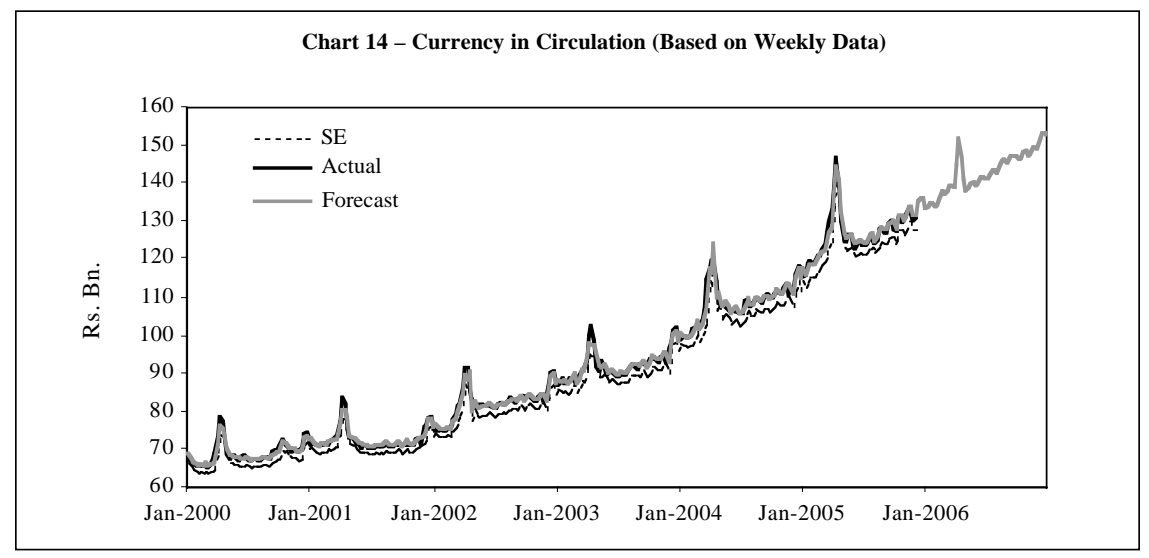

$7 /$ This date varies with the weekend, and other holidays that occur.

8/ The first quarter average for 2006 in the monthly model (Rs. 134.3 billion) is more or less the same as the forecast by the weekly model (Rs.134.57 billion). 


\section{Estimation with Daily Data}

The intra-month variations with weekly data suggest significant but small variations among the weekly demands. Therefore, it is important to identify the day of the month effect and, if any, intra week variations. Furthermore, some systematic estimate of daily currency demand is useful for daily liquidity estimates to be used in open market operations.

To estimate the effect of each day of the month separately, the regression has done without the constant term in the empirical specification. The daily effect has been captured by the $a j(j=1,2,3,4, \ldots 30,31)$ respectively. In the empirical specification, a few more variables have been added to capture the effect of bank holidays, harvesting period and festivals.

The regression results reported below find evidence in favour of some of the earlier findings for monthly and weekly data. More importantly, the results reveal that there is a pronounced day of the month effect in the growth rates of currency in circulation. Chart 15 presents the graph of estimated $D j$ as a function of $j(1,2,3, \ldots 30,31)$. Starting from a positive value at $j=1$, estimated $D j$ begins to increase after the $3^{\text {rd }}$ day of a month. The results show that currency in circulation increases at a higher rate after the $7^{\text {th }}$ day of the month the time close to the date that government salary advances are paid. The seasonal co-efficient increases gradually and remains around its peak during the $14^{\text {th }}$ to $21^{\text {st }}$ day of the month. Though the seasonal co-efficient starts to decline thereafter, it continues to remain high until the $23^{\text {rd }}$ day of the month. Since the lowest demand is evident during the first and last week of the month, the results agree with the findings from weekly data (Section 3.2).

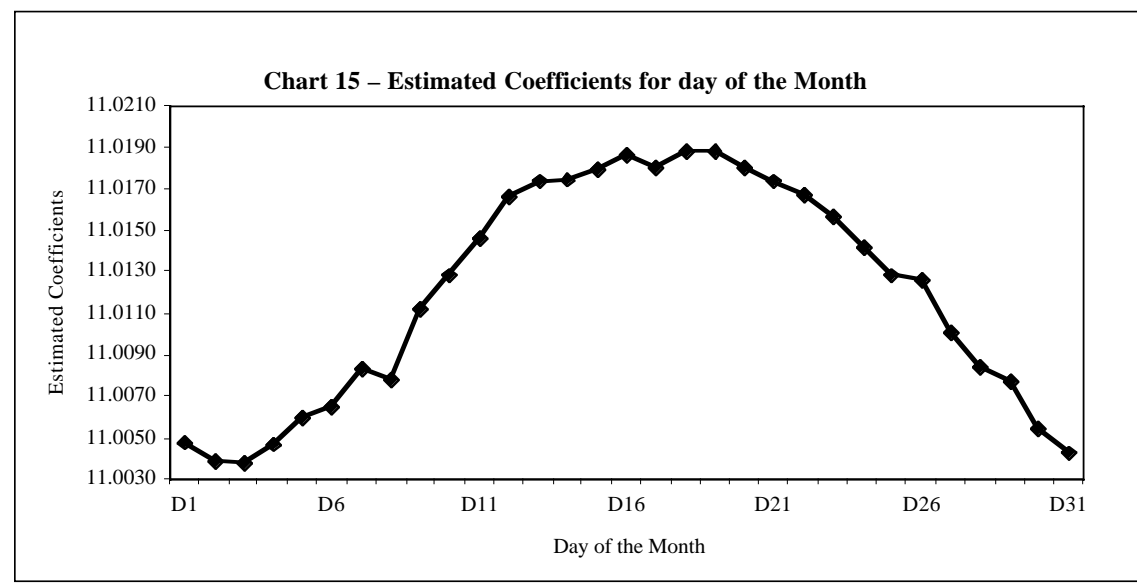


The estimated equation also shows that the effect of the Sinhala/Tamil New Year festival is strong. The variable which indicates a day prior to a holiday represents all religious and other bank holidays other than the Sinhala/Tamil New Year holidays and Christmas holidays. The alternative variable, viz, the trading day effect, better represents the data than the holiday variable. The Christmas holiday is significant only at the 10 per cent level of significance in the model and was subsequently dropped from all specifications. Neither election days nor harvesting season found significance in this model.

$$
\begin{aligned}
& \text { LCURRENCY }=0.0003 * \text { TIME }+11.0048 * \mathrm{~A} 1+11.0039 * \mathrm{~A} 2 \\
& \text { (17.0191) (428.1711) (428.1503) } \\
& +11.0038 * \mathrm{~A} 3+11.0047 * \mathrm{~A} 4+11.0060 * \mathrm{~A} 5+11.0065 * \mathrm{~A} 6 \\
& \begin{array}{llll}
(428.1704) \quad(428.2245) \quad(428.2907) \quad(428.3446)
\end{array} \\
& +11.0083 * \mathrm{~A} 7+11.0098 * \mathrm{~A} 8+11.0112 * \mathrm{~A} 9+11.0129 * \mathrm{~A} 10
\end{aligned}
$$

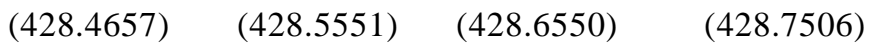

$$
\begin{aligned}
& +11.0147 * \mathrm{~A} 11+11.01667 * \mathrm{~A} 12+11.01744 * \mathrm{~A} 13+11.0175 * \mathrm{~A} 14 \\
& \begin{array}{llll}
(428.8540) & (428.9577) \quad(429.0125) \quad \text { (429.0326) }
\end{array} \\
& \begin{array}{c}
11.0180 * \mathrm{~A} 15+11.0187 * \mathrm{~A} 16+11.0181 * \mathrm{~A} 17+11.01891 * \mathrm{~A} 18 \\
(429.0657) \\
(429.0993)
\end{array} \\
& +11.0189 * \mathrm{~A} 19+11.0181 * \mathrm{~A} 20+11.01742 * \mathrm{~A} 21+11.0167 * \mathrm{~A} 22
\end{aligned}
$$

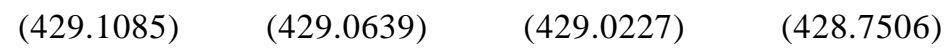

$$
\begin{aligned}
& +11.01565 * \mathrm{~A} 23+11.01426 * \mathrm{~A} 24+11.01289 * \mathrm{~A} 25 \\
& \text { (428.9007) (428.8061) (428.7023) } \\
& +11.01264 * \mathrm{~A} 26+11.0101 * \mathrm{~A} 27+11.0084 * \mathrm{~A} 28+11.0077 * \mathrm{~A} 29
\end{aligned}
$$

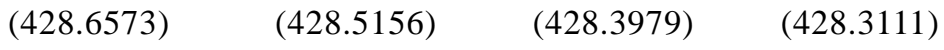

$$
\begin{aligned}
& +11.0055 * \mathrm{~A} 30+11.0042 * \mathrm{~A} 31+0.0039 * \text { NEWYEAR } \\
& \text { (428.1742) (428.0558) (3.6354) } \\
& +0.0026 * \text { CHRISTMAS }+0.001157 * \text { Holiday }+[\text { AR }(1)=0.9822 \text {, } \\
& \text { (1.5252) (4.4798) (236.5869) }
\end{aligned}
$$$$
\mathrm{MA}(1)=0.0327, \mathrm{MA}(2)=0.0009, \operatorname{MA}(3)=0.1092, \mathrm{MA}(4)=0.1008 \text {, }
$$
(2.5909)
$(0.0431)$
(5.3187)
(4.8833) 


$$
\begin{aligned}
& \operatorname{MA}(5)=0.0255, \operatorname{MA}(6)=0.0796, \operatorname{MA}(7)=0.3982] \\
& (1.2452) \quad(3.8728) \quad(19.3518) \ldots \ldots \ldots \\
& R^{2}=0.9993 \quad \text { AIC }=-7.5103 \quad \text { SCI }=-7.3932 \quad \text { DW }=1.9914
\end{aligned}
$$

The equation explains the variation in the currency in circulation very well. The Adjusted $\mathrm{R}^{2}$ is almost $100 \%$. The value of Durbin Watson statistic is very close to 2, implying the residuals are free of first order auto correlation. Further examination of the residuals does not indicate the presence of auto correlation or partial autocorrelation after including ARMA $(1,7)$ lags. SCI and AIC statistics are negative and small.

The residual plot in Chart 16 reveals no pattern and looks like white noise. The residual sample auto correlations and partial auto correlations display no patterns and are mostly inside the Bartlett bands. The Ljung-Box statistics are also good for small and moderate displacements. The histogram and normality test suggest that the residuals appear to be fairly well approximated by a normal distribution.

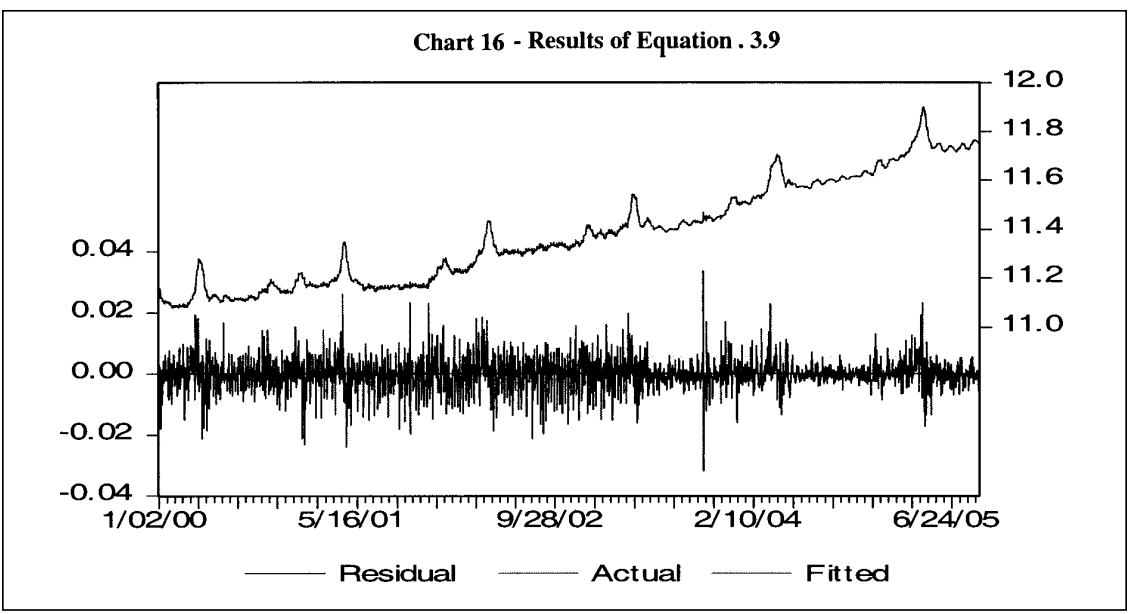

\section{Forecast Based on Daily Data}

The model was used to generate estimates of currency in circulation for past periods and to obtain 3 month- ahead extrapolation forecasts for October December 2005. Actual daily data for 1 October - 7 November 2005 were used for post sample validity tests. The forecast looks reasonable. It is visually 
apparent that the model has the ability to pick up seasonal patterns that dominate the local behaviour of the series. Chart 17 shows actual historical data for 1 January - 7 November 2005 and the forecast. Post sample estimates for 1 October -7 November 2005 are used for testing the validity of the model.

The results shown in Annex 2 indicate that post sample estimates are very close to the actual data. It also indicates that the model based on daily data can produce more accurate estimate for the short run than the model based on monthly data. The forecasting error for the out of sample period was 0.4432 , which is much smaller than those produced by the models based on monthly and weekly data. Further, the estimated monthly average currency in circulation based on daily forecasts is very close to the estimate based on monthly data.

Table 3 - Comparison of Forecasts (Post Sample Estimates)

Rs. Billion

\begin{tabular}{|l|c|c|c|c|}
\hline & $\begin{array}{c}\text { Actual } \\
\text { Data }\end{array}$ & $\begin{array}{c}\text { Model Based on } \\
\text { Monthly averages }\end{array}$ & $\begin{array}{c}\text { Model Based on } \\
\text { Weekly averages }\end{array}$ & $\begin{array}{c}\text { Model Based on } \\
\text { Daily data }\end{array}$ \\
\hline Sept-2005 & 128.4 & 127.9 & 128.3 & 128.4 \\
Oct-2005 & 129.4 & 129.6 & 129.1 & 129.2 \\
Nov-2005 & 131.8 & 132.1 & 131.5 & 131.8 \\
Dec-2005 & 134.3 & 134.2 & 133.2 & 133.9 \\
Jan-2006 & 132.9 & 133.4 & 133.6 & 132.8 \\
Feb-2006 & & 132.4 & 133.2 & 132.7 \\
\hline
\end{tabular}

(a) The forecast based on average weekly data cannot be compared directly with the forecast based on average monthly data in certain months as some weeks partly fall into another month.

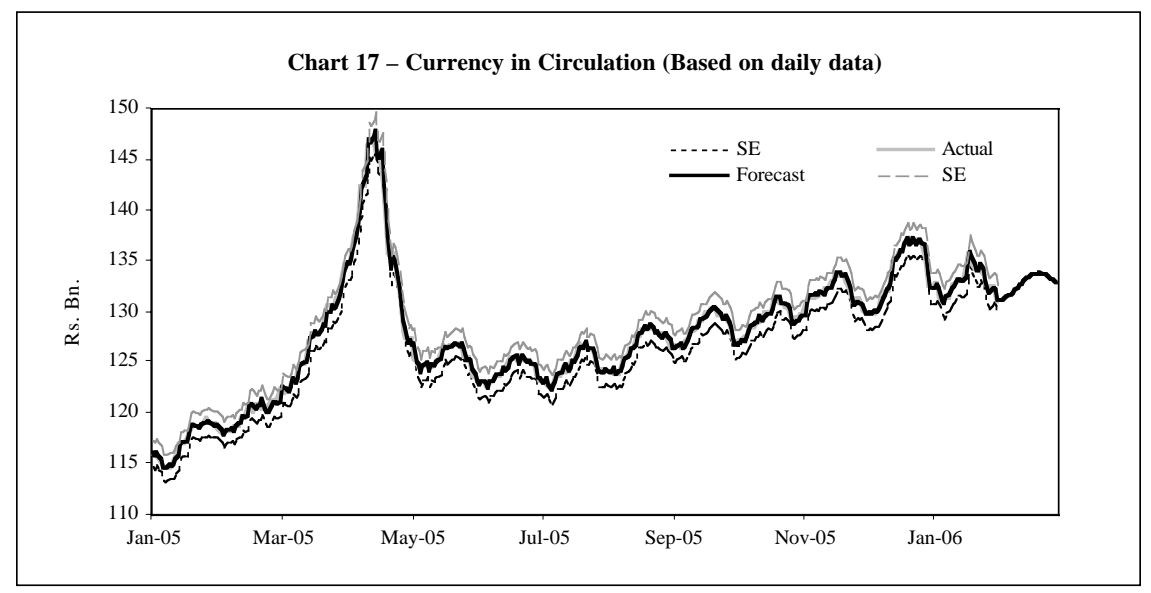


Chart 17 shows historical data on currency in circulation and three months ahead extrapolation forecasts for 1 September 2005 to 28 February 2006. To help visual interpretation, only 9 months of past data are shown in the Chart. The model has performed well in picking up seasonal patterns that dominate the local behaviour of currency in circulation.

\section{An Interpretation of the Econometric Results}

According to all validity tests explained in Section 3, all three models, based on monthly, weekly and daily data have tracked well the past movements both within and outside the sample period. Therefore, these models can be used to explain the seasonal effects within the year and within the month. They are also useful to identify the cultural, social and economic factors that influence the demand for currency.

\section{A. Seasonal Effect}

To identify the seasonal impact on currency in circulation in relation to January, Equation 3.7 reported above was re- estimated with a constant term. To avoid the dummy variable trap, the monthly effect has been captured by the dummy variables for February to December. Therefore, the estimated coefficients for dummy variables are incremental month effects relative to January of each year. In this model the intercept represents the effect on January, the base month. Accordingly, the significance of monthly differential coefficients for each month should not matter much as it simply states that the variation in currency in circulation from the base is significant.

More specifically, the coefficient of D2, i.e., 0.096, states that, holding all effects constant, the average value of the log of ratio of currency in circulation will be higher than January by 0.096 during the month of February. Given these differential coefficients, one can easily arrive at an average value for each month by adding specific differential coefficients to the base. The interpretation can be made easier by specifying the left hand side of the equation as follows.

$$
\begin{aligned}
\mathrm{D}[\log (\text { Currency) }] & =\log \left(\text { Currency }_{t}\right)-\log \left(\text { Currency }_{t-1}\right) \\
& =\log \left\{\frac{\text { Currency }_{t}}{\text { Currency }_{t-1}}\right\} \\
& \cong \frac{\text { Currency }}{\text { Currency }}
\end{aligned}
$$


In this case, the left hand side of the equation is simply the natural log of the ratio of currency in circulation in two successive months. The original series is thus transformed into a chain of log ratios of currency stocks in consecutive months. Following Halvorsen and Palmquist (1980), differential coefficients are transformed to show differential effects in terms of percentage change. The relative effect for each month is calculated with the help of an exponential transformation and further multiplied by 100 to show percentage changes as noted in Table 4.

Table 4 - Effect of Seasonal and other Selected Variables on Currency in Circulation

\begin{tabular}{|l|l|c|r|c|}
\hline \multicolumn{1}{|c|}{ Months } & Variable & Coefficient & t-Statistic & Per cent Effect \\
\hline January & C & -0.0311 & -4.2515 & \\
February & D2 & 0.0096 & 1.3162 & 0.9597 \\
March & D3 & 0.0468 & 6.1355 & 4.7883 \\
April & D4 & 0.0986 & 13.3109 & 10.3578 \\
May & D5 & -0.0739 & -10.1766 & -7.1237 \\
June & D6 & 0.0063 & 0.8310 & 0.6309 \\
July & D7 & 0.0236 & 2.9282 & 2.3890 \\
August & D8 & 0.0311 & 3.9880 & 3.1556 \\
September & D9 & 0.0260 & 3.4304 & 2.6306 \\
October & D10 & 0.0250 & 3.2416 & 2.5336 \\
November & D11 & 0.0187 & 2.5012 & 1.8895 \\
December & D12 & 0.0560 & 7.5153 & 5.7564 \\
Holiday & HOLI & 0.0061 & 3.5917 & 0.6079 \\
Election & ELECTION & 0.0280 & 4.0093 & 2.8410 \\
\hline
\end{tabular}

The relative effect for January is $g=\left(\mathrm{e}^{-0.0311}-1\right)$ or in per cent term

$$
g * 100=\left(\mathrm{e}^{-0.0311}-1\right) * 100
$$

The relative effects represent percentage changes in the average monthly ratio of stock of currency For example; the average ratio of stock of currency in February will be 1 per cent higher than the average in the base month, January. Similarly the average ratio of the stock of currency will be 10.36 per cent higher in April than in January. 


\section{B. Sinhala and Tamil New Year Effect}

In a model with monthly data, the seasonal dummy for April and December are the same as the dummy variables that represent the Sinhala/Tamil New Year and Christmas, respectively. Although the highly significant coefficient in April is mostly due to the effect of the New Year demand, it is practically impossible to isolate the effect from the seasonal effect. Equation 3.8 and Equation 3.9 too, which represent models for weekly and daily data, respectively, confirm that the Sinhala/Tamil New Year has significant impact on currency in circulation. Estimates based on the daily model, reveal that the effect of Sinhala/Tamil New Year on currency in circulation is around 9.96 per cent in April. ${ }^{9}$

Furthermore, any additional holiday on particular month increases currency in circulation by 0.61 per cent.

\section{Christmas Effect}

As in the case of the Sinhala/Tamil New Year, the effect of Christmas on currency in circulation could not be captured implicitly in models with weekly data as Christmas falls on different days in different years. However, in the Halvorsen and Palmquist type analysis based on monthly data explained above, the effect of the Christmas demand is represented by the dummy for December. Accordingly, ceteris paribus, the effect of seasonality in December is approximately 5.8 per cent over the level in January. The daily model suggests that the Christmas effect is around 4 per cent. The balance seasonal effect may be due to high spending associated with school and year end vacations and December $31^{\text {st }}$ celebrations.

The holiday effect has an additional increment over the seasonal effect on the average ratio of stock of currency in circulation depending on the number of holidays that fall in December.

\section{Holiday Effect}

The effect of the number of holidays on currency in circulation is significant in all three models. As noted in Table 5, the average ratio of currency in circulation will change significantly if an additional holiday other than

9/ The effect of the Sinhala/Tamil New Year festival on a particular day, which is estimated by the daily model, is weighted with the dummy variable for the New Year festival. The dummy variable is defined based on the last 5 years' average of currency in circulation in April each year. 
Saturday and Sunday also falls in that month. For example, if the month of February has an additional holiday, the average ratio of stock of currency in circulation will be 0.61 per cent higher than the mean value of January; in addition to the 1 per cent. That is, in total, this will be 1.61 per cent higher than the base.

\section{E. Effect of Elections}

Similarly, if an election falls in a particular month, the additional change will be 2.8 per cent higher than the normal increment of that particular month. For example, if an election falls in December, the average ratio of stock of currency will be 2.8 per cent higher than the mean value of January in addition to the 5.8 per cent. For example, in December 2001, when the Presidential election was held, the monthly average of currency in circulation increased by 7.9 per cent. This growth is very close to the results shown in the study (i.e., $5.76+2.84+(3 * 0.61)-3.07=7.4 \%)$.

\section{Conclusion}

The paper presents three models suitable for forecasting currency in circulation, based on monthly, weekly and daily data for the period of 1 January 2000 to 30 September 2005. The data for the period 1 October -30 November 2005 were used for post sample validity tests. The forecasts produced by all three models accurately matches the shape of the monthly, weekly and daily oscillations, respectively, and capture the trend, seasonal and cyclical effects well. Post sample estimation error is very small and remained less than 1 per cent in all models. The forecasts based on the daily and monthly models performed very well, predicting very similar results, and were close to realized data $^{10}$ when used within sample.

The models evidenced clear seasonality in April and December mainly associated with the Sinhala/Tamil New Year and Christmas respectively. In addition, the number of special holidays in a particular month significantly affects currency in circulation. Similarly, having a general election also has significant impact on currency demand. The models based on weekly and daily data clearly indicated high seasonal demand around the $10^{\text {th }}-23^{\text {rd }}$ day (mainly $2^{\text {nd }}$ and $3^{\text {rd }}$ week) of the month.

10/ Estimates based on weekly data are not used in comparing with the other two models due to the interpretation difficulties as the particular week does not include the comparable days and a particular month does not contain an equal number of weeks. 
The application of these models and their results may have important implications to researchers and policy makers. The CBSL can particularly benefit by incorporating this method in disaggregating its annual monetary targets into monthly targets thereby smoothening the implementation of its monetary policy.

Systematic projection of currency in circulation is always an important part of the liquidity forecasting mechanism of the Central Bank. Using these results, the demand for liquidity in specific months can be projected with lower error and therefore, subsequent injections or withdrawals through open market operations are likely to lead to better targeting of monetary aggregates.

Nevertheless, it is important to note that a central bank cannot depend purely or mechanically on forecasting models to predict currency in circulation to be used in liquidity management. As currency in circulation is subject to the influence of various unforeseen developments in the economy, including one off events such as the Tsunami, and the September $11^{\text {th }}$ attack in the USA, close monitoring of day to day developments is extremely important. Even in developed economies, like the USA and UK, central banks continuously develop and use time series and structural models to forecast currency demand, but review market conditions daily and do necessary adjustments manually to make the assessment more realistic. 


\section{References}

Bhattacharya, K. and Joshi Himanshu M. (2001), "Modelling Currency in Circulation in India", Applied Economic Letters, 8: 585-592.

Diebold, F. X. (2004), Elements of forecasting, Third Edition, Thomson-South Western Publishers, Canada.

Diebold, F. X. and Watson, M. W. (1998), "New Developments in Economic Forecasting", Special issue of Journal of Applied Econometrics, 453-594.

Garderen, Kees Janvan and Chandra Shah (2002), "The Interpretation of Dummy Variables in Semi Logarithmic Equations in the presence of Estimation Uncertainty", University of Van Amsterdam discussion Paper.

Halvorsen, R. and Palmquisit, R. (1980), "The Interpretation of Dummy Variables in Semi Logarithmetic of Equations", American Economic Review, Vol. 70(3), 474-475.

Riazuddin Riaz and Mohamood ul Husam Khan (2002), "Detection and forecasting of Islamic Calendar Effects in time Series Data", State Bank of Pakistan working papers, No.2.

Tillers Ivars (2002), Time Series Modelling of the Daily Currency in Circulation, University of Latvia. 
Annex - 1

Forecast Results (Weekly Data)

\begin{tabular}{|c|c|c|c|c|c|c|}
\hline \multirow{2}{*}{$\begin{array}{l}\text { Week } \\
\text { Ending }\end{array}$} & \multicolumn{3}{|c|}{ (Rs. Billion) } & \multirow{2}{*}{$\begin{array}{c}\text { As a } \\
(\%)\end{array}$} & \multirow{2}{*}{$\begin{array}{l}\text { Week } \\
\text { Ending }\end{array}$} & \multirow{2}{*}{$\begin{array}{c}\text { Forcast } \\
\text { (Rs.Billion) }\end{array}$} \\
\hline & Actual & $\begin{array}{c}\text { Fore- } \\
\text { cast }\end{array}$ & $\begin{array}{l}\text { Diffe } \\
\text {-rence }\end{array}$ & & & \\
\hline 2-Sep-05 & 126.9 & 127.2 & 0.3 & 0.3 & 3-Feb-06 & 132.2 \\
\hline 9-Sep-05 & 127.1 & 127.3 & 0.2 & 0.2 & 10-Feb-06 & 131.7 \\
\hline 16-Sep-05 & 129.1 & 128.4 & -0.7 & -0.5 & 17-Feb-06 & 133.2 \\
\hline 23-Sep-05 & 130.0 & 129.1 & -0.9 & -0.7 & 24-Feb-06 & 135.5 \\
\hline $30-$ Sep-05 & 128.0 & 129.3 & 1.3 & 1.0 & 3-Mar-06 & 134.8 \\
\hline 7-Oct-05 & 127.6 & 127.0 & -0.6 & -0.5 & 10-Mar-06 & 135.3 \\
\hline 14-Oct-05 & 129.2 & 128.0 & -1.1 & -0.9 & 17-Mar-06 & 137.0 \\
\hline 21-Oct-05 & 130.9 & 130.6 & -0.3 & -0.2 & 24-Mar-06 & 137.0 \\
\hline 28-Oct-05 & 129.8 & 130.6 & 0.8 & 0.7 & 31-Mar-06 & 138.4 \\
\hline 4-Nov-05 & 130.6 & 129.4 & -1.2 & -0.9 & & \\
\hline 11-Nov-05 & 131.7 & 130.5 & -1.2 & -0.9 & & \\
\hline 18-Nov-05 & 133.3 & 133.1 & -0.2 & -0.1 & & \\
\hline 25-Nov-05 & 131.8 & 132.9 & 1.1 & 0.9 & & \\
\hline 2-Dec-05 & 130.0 & 130.9 & 0.8 & 0.6 & & \\
\hline 9-Dec-05 & 130.9 & 130.5 & -0.4 & -0.3 & & \\
\hline 16-Dec-05 & 134.8 & 134.1 & -0.7 & -0.5 & & \\
\hline 23-Dec-05 & 137.0 & 134.8 & -2.2 & -1.6 & & \\
\hline 30-Dec-05 & 135.1 & 135.8 & 0.7 & 0.5 & & \\
\hline 06-Jan-06 & 131.8 & 133.4 & 1.5 & 1.2 & & \\
\hline 13-Jan-06 & 132.6 & 132.7 & 0.1 & 0.1 & & \\
\hline 20-Jan-06 & 134.9 & 133.5 & -1.4 & -1.0 & & \\
\hline 27-Jan-06 & 133.0 & 134.8 & 1.8 & 1.4 & & \\
\hline $\begin{array}{l}\text { SER (with in } \\
\text { sample) }\end{array}$ & & & 1.0001 & & & \\
\hline $\begin{array}{l}\text { Out sample } \\
\text { Forecast error }\end{array}$ & & & & & & 1.044 \\
\hline
\end{tabular}


Annex 2

Forecast Results (Daily Data)

\begin{tabular}{|c|c|c|c|c|c|c|c|c|c|}
\hline \multirow[b]{2}{*}{ Date } & \multicolumn{2}{|c|}{ Rs. Billion } & \multicolumn{2}{|c|}{ Difference } & \multirow[b]{2}{*}{ Date } & \multicolumn{2}{|c|}{ Rs. Billion } & \multicolumn{2}{|c|}{ Difference } \\
\hline & Actual & $\begin{array}{c}\text { Fore- } \\
\text { cast }\end{array}$ & Rs. bn & $\begin{array}{c}\text { As a } \\
\%\end{array}$ & & Actual & $\begin{array}{c}\text { Fore- } \\
\text { cast }\end{array}$ & Rs. bn & $\begin{array}{c}\text { As a } \\
\%\end{array}$ \\
\hline 1-Sep & 126.4 & 126.4 & 0.1 & 0.1 & 10-Oct & 128.7 & 129.0 & 0.2 & 0.2 \\
\hline 2-Sep & 126.7 & 126.3 & -0.4 & -0.3 & 11-Oct & 129.1 & 129.0 & -0.1 & -0.1 \\
\hline 3-Sep & 126.7 & 126.6 & -0.1 & -0.1 & 12 -Oct & 128.9 & 129.5 & 0.6 & 0.5 \\
\hline 4-Sep & 126.7 & 126.8 & 0.1 & 0.1 & 13-Oct & 129.3 & 129.0 & -0.3 & -0.2 \\
\hline 5-Sep & 126.5 & 127.0 & 0.5 & 0.4 & 14-Oct & 129.9 & 129.4 & -0.4 & -0.3 \\
\hline 6-Sep & 126.6 & 126.4 & -0.2 & -0.1 & 15-Oct & 129.9 & 129.6 & -0.2 & -0.2 \\
\hline 7-Sep & 127.0 & 126.5 & -0.5 & -0.4 & 16-Oct & 129.9 & 129.8 & -0.1 & -0.1 \\
\hline 8-Sep & 127.4 & 127.2 & -0.2 & -0.2 & 17-Oct & 129.9 & 129.8 & -0.1 & -0.1 \\
\hline 9-Sep & 128.1 & 127.7 & -0.4 & -0.3 & 18-Oct & 131.1 & 130.2 & -0.9 & -0.7 \\
\hline 10-Sep & 128.1 & 128.3 & 0.2 & 0.1 & 19-Oct & 131.4 & 131.0 & -0.4 & -0.3 \\
\hline 11-Sep & 128.1 & 128.4 & 0.2 & 0.2 & 20-Oct & 131.3 & 131.4 & 0.1 & 0.1 \\
\hline 12-Sep & 128.4 & 128.4 & 0.1 & 0.1 & 21-Oct & 130.8 & 131.5 & 0.7 & 0.5 \\
\hline 13-Sep & 129.1 & 128.6 & -0.5 & -0.4 & 22-Oct & 130.8 & 130.8 & 0.0 & 0.0 \\
\hline 14-Sep & 129.1 & 129.3 & 0.2 & 0.2 & 23-Oct & 130.8 & 130.8 & -0.1 & 0.0 \\
\hline 15-Sep & 129.1 & 129.2 & 0.1 & 0.1 & 24-Oct & 130.4 & 130.8 & 0.4 & 0.3 \\
\hline 16-Sep & 129.9 & 129.4 & -0.5 & -0.4 & 25-Oct & 130.2 & 130.6 & 0.4 & 0.3 \\
\hline 17-Sep & 129.9 & 129.6 & -0.3 & -0.2 & 26-Oct & 129.5 & 130.3 & 0.8 & 0.6 \\
\hline 18-Sep & 129.9 & 129.9 & 0.0 & 0.0 & 27-Oct & 129.3 & 129.0 & -0.3 & -0.2 \\
\hline 19-Sep & 130.2 & 130.1 & -0.1 & -0.1 & 28 -Oct & 129.5 & 128.8 & -0.7 & -0.5 \\
\hline $20-$ Sep & 130.5 & 130.4 & -0.1 & -0.1 & 29-Oct & 129.5 & 129.2 & -0.3 & -0.3 \\
\hline 21-Sep & 130.2 & 130.3 & 0.1 & 0.1 & $30-O c t$ & 129.5 & 129.2 & -0.3 & -0.3 \\
\hline 22-Sep & 129.6 & 130.1 & 0.4 & 0.3 & $31-\mathrm{Oct}$ & 129.8 & 129.4 & -0.4 & -0.3 \\
\hline 23-Sep & 129.5 & 129.7 & 0.2 & 0.2 & 1-Nov & 129.8 & 129.6 & -0.2 & -0.1 \\
\hline 24-Sep & 129.5 & 129.3 & -0.2 & -0.2 & 2-Nov & 130.7 & 129.6 & -1.1 & -0.8 \\
\hline $25-S e p$ & 129.5 & 129.3 & -0.2 & -0.2 & 3-Nov & 131.2 & 131.0 & -0.3 & -0.2 \\
\hline 26-Sep & 129.3 & 129.6 & 0.4 & 0.3 & 4-Nov & 131.2 & 131.6 & 0.3 & 0.2 \\
\hline 27-Sep & 128.7 & 128.9 & 0.2 & 0.2 & 5-Nov & 131.2 & 131.7 & 0.4 & 0.3 \\
\hline 28-Sep & 127.8 & 128.5 & 0.7 & 0.5 & 6-Nov & 131.2 & 131.6 & 0.3 & 0.3 \\
\hline 29-Sep & 127.1 & 127.5 & 0.4 & 0.3 & 7-Nov & 131.3 & 131.8 & 0.5 & 0.3 \\
\hline 30-Sep & 127.0 & 126.7 & -0.3 & -0.2 & 8-Nov & 131.4 & 131.6 & 0.2 & 0.2 \\
\hline 1-Oct & 127.0 & 126.8 & -0.2 & -0.2 & 9-Nov & 131.6 & 131.9 & 0.2 & 0.2 \\
\hline $2-\mathrm{Oct}$ & 127.0 & 126.9 & -0.1 & -0.1 & $10-\mathrm{Nov}$ & 131.7 & 131.8 & 0.1 & 0.1 \\
\hline 3-Oct & 127.3 & 127.0 & -0.3 & -0.2 & $11-\mathrm{Nov}$ & 132.3 & 131.7 & -0.7 & -0.5 \\
\hline 4-Oct & 127.2 & 127.3 & 0.2 & 0.1 & $12-\mathrm{Nov}$ & 132.3 & 132.2 & -0.2 & -0.1 \\
\hline 5-Oct & 127.5 & 127.1 & -0.4 & -0.3 & 13-Nov & 132.3 & 132.2 & -0.1 & -0.1 \\
\hline 6-Oct & 127.6 & 127.5 & -0.1 & -0.1 & $14-\mathrm{Nov}$ & 132.9 & 132.3 & -0.6 & -0.4 \\
\hline $7-\mathrm{Oct}$ & 128.4 & 128.0 & -0.4 & -0.3 & $15-\mathrm{Nov}$ & 132.9 & 132.8 & -0.1 & -0.1 \\
\hline $8-O c t$ & 128.4 & 128.6 & 0.2 & 0.1 & $16-\mathrm{Nov}$ & 133.7 & 133.1 & -0.6 & -0.5 \\
\hline 9-Oct & 128.4 & 128.7 & 0.3 & 0.2 & 17-Nov & 133.4 & 133.7 & 0.3 & 0.2 \\
\hline
\end{tabular}

(Contd.) 


\begin{tabular}{|c|c|c|c|c|c|c|c|c|c|}
\hline \multirow[b]{2}{*}{ Date } & \multicolumn{2}{|c|}{ Rs. Billion } & \multicolumn{2}{|c|}{ Difference } & \multirow[b]{2}{*}{ Date } & \multicolumn{2}{|c|}{ Rs. Billion } & \multicolumn{2}{|c|}{ Difference } \\
\hline & Actual & $\begin{array}{c}\text { Fore- } \\
\text { cast }\end{array}$ & Rs. bn & $\begin{array}{c}\text { As a } \\
\%\end{array}$ & & Actual & $\begin{array}{c}\text { Fore- } \\
\text { cast }\end{array}$ & Rs. bn & $\begin{array}{c}\text { As a } \\
\%\end{array}$ \\
\hline 18-Nov & 133.4 & 133.8 & 0.4 & 0.3 & 31-Dec & 132.4 & 132.3 & 1.1 & 0.8 \\
\hline 19-Nov & 133.4 & 133.4 & 0.0 & 0.0 & 1-Jan & 132.4 & 132.2 & -0.2 & -0.1 \\
\hline 20-Nov & 133.4 & 133.4 & 0.0 & 0.0 & 2-Jan & 132.8 & 132.2 & -0.3 & -0.2 \\
\hline 21-Nov & 132.9 & 133.6 & 0.7 & 0.5 & 3-Jan & 132.7 & 132.6 & -0.6 & -0.5 \\
\hline 22-Nov & 132.3 & 132.8 & 0.5 & 0.4 & 4-Jan & 131.4 & 132.2 & -0.1 & -0.1 \\
\hline 23-Nov & 131.6 & 132.3 & 0.7 & 0.5 & 5-Jan & 131.0 & 131.2 & 0.8 & 0.6 \\
\hline 24-Nov & 131.0 & 131.2 & 0.2 & 0.1 & 6-Jan & 131.3 & 130.7 & 0.2 & 0.1 \\
\hline $25-\mathrm{Nov}$ & 131.2 & 130.5 & -0.6 & -0.5 & 7-Jan & 131.3 & 131.4 & -0.6 & -0.4 \\
\hline 26-Nov & 131.2 & 130.9 & -0.3 & -0.2 & 8-Jan & 131.3 & 131.5 & 0.2 & 0.1 \\
\hline 27-Nov & 131.2 & 130.7 & -0.5 & -0.4 & 9-Jan & 132.0 & 131.9 & 0.3 & 0.2 \\
\hline 28-Nov & 130.8 & 130.8 & 0.1 & 0.0 & 10-Jan & 132.6 & 132.2 & 0.0 & 0.0 \\
\hline 29-Nov & 130.2 & 130.5 & 0.4 & 0.3 & 11-Jan & 132.6 & 132.4 & -0.4 & -0.3 \\
\hline 30-Nov & 129.7 & 129.7 & 0.0 & 0.0 & 12-Jan & 132.9 & 133.0 & -0.2 & -0.2 \\
\hline 1-Dec & 129.8 & 129.7 & 0.0 & 0.0 & 13-Jan & 132.9 & 133.2 & 0.1 & 0.1 \\
\hline 2-Dec & 129.7 & 129.9 & -0.1 & -0.1 & 14-Jan & 132.9 & 132.9 & 0.2 & 0.2 \\
\hline 3-Dec & 129.7 & 129.7 & 0.2 & 0.2 & 15-Jan & 132.9 & 132.9 & 0.0 & 0.0 \\
\hline 4-Dec & 129.7 & 130.1 & 0.0 & 0.0 & 16-Jan & 134.7 & 133.2 & 0.0 & 0.0 \\
\hline 5-Dec & 130.1 & 130.0 & 0.3 & 0.2 & 17-Jan & 135.8 & 134.8 & -1.4 & -1.1 \\
\hline 6-Dec & 130.1 & 130.0 & -0.1 & -0.1 & 18-Jan & 135.2 & 136.0 & -1.0 & -0.7 \\
\hline 7-Dec & 131.0 & 130.4 & -0.1 & -0.1 & 19-Jan & 134.6 & 135.3 & 0.8 & 0.6 \\
\hline 8-Dec & 131.4 & 131.3 & -0.6 & -0.5 & 20-Jan & 134.1 & 134.6 & 0.8 & 0.6 \\
\hline 9-Dec & 132.0 & 131.6 & -0.2 & -0.1 & 21-Jan & 134.1 & 133.9 & 0.5 & 0.4 \\
\hline 10-Dec & 132.0 & 132.2 & -0.4 & -0.3 & 22-Jan & 134.1 & 134.0 & -0.2 & -0.1 \\
\hline 11-Dec & 132.0 & 132.2 & 0.2 & 0.1 & 23-Jan & 134.0 & 134.6 & -0.1 & -0.1 \\
\hline 12-Dec & 133.3 & 132.5 & 0.2 & 0.2 & 24-Jan & 133.5 & 134.1 & 0.6 & 0.5 \\
\hline 13-Dec & 134.8 & 133.5 & -0.7 & -0.6 & 25-Jan & 132.7 & 133.0 & 0.5 & 0.4 \\
\hline 14-Dec & 135.0 & 135.1 & -1.3 & -1.0 & 26-Jan & 132.4 & 132.2 & 0.4 & 0.3 \\
\hline 15-Dec & 135.0 & 135.0 & 0.1 & 0.1 & 27-Jan & 132.4 & 131.8 & -0.2 & -0.1 \\
\hline 16-Dec & 136.0 & 135.6 & 0.0 & 0.0 & 28-Jan & 132.4 & 132.1 & -0.6 & -0.5 \\
\hline 17-Dec & 136.0 & 136.1 & -0.4 & -0.3 & 29-Jan & 132.4 & 132.3 & -0.1 & -0.1 \\
\hline 18-Dec & 136.0 & 136.0 & 0.1 & 0.1 & 30-Jan & 131.4 & 132.1 & 0.8 & 0.6 \\
\hline 19-Dec & 136.9 & 136.5 & 0.0 & 0.0 & 31-Jan & 131.0 & 131.1 & 0.1 & 0.1 \\
\hline 20-Dec & 136.9 & 137.2 & -0.3 & -0.2 & 1-Feb & & 131.1 & & \\
\hline 21-Dec & 136.9 & 136.6 & 0.4 & 0.3 & 2-Feb & & 131.0 & & \\
\hline 22-Dec & 137.3 & 136.8 & -0.2 & -0.2 & 3-Feb & & 131.3 & & \\
\hline 23-Dec & 137.1 & 137.2 & -0.5 & -0.4 & 4-Feb & & 131.4 & & \\
\hline 24-Dec & 137.1 & 136.6 & 0.1 & 0.1 & 5-Feb & & 131.6 & & \\
\hline 25-Dec & 137.1 & 136.9 & -0.5 & -0.4 & 6-Feb & & 131.5 & & \\
\hline 26-Dec & 137.1 & 137.1 & -0.2 & -0.1 & 7-Feb & & 131.8 & & \\
\hline 27-Dec & 136.8 & 136.7 & 0.0 & 0.0 & 8-Feb & & 132.0 & & \\
\hline 28-Dec & 135.4 & 136.7 & -0.1 & 0.0 & 9-Feb & & 132.2 & & \\
\hline 29-Dec & 133.9 & 135.1 & 1.3 & 0.9 & $10-\mathrm{Feb}$ & & 132.5 & & \\
\hline 30-Dec & 132.4 & 133.5 & 1.2 & 0.9 & $11-\mathrm{Feb}$ & & 132.7 & & \\
\hline
\end{tabular}




\begin{tabular}{|c|c|c|c|c|c|c|c|c|c|}
\hline \multirow[b]{2}{*}{ Date } & \multicolumn{2}{|c|}{ Rs. Billion } & \multicolumn{2}{|c|}{ Difference } & \multirow[b]{2}{*}{ Date } & \multicolumn{2}{|c|}{ Rs. Billion } & \multicolumn{2}{|c|}{ Difference } \\
\hline & Actual & $\begin{array}{l}\text { Fore- } \\
\text { cast }\end{array}$ & Rs. bn & $\begin{array}{c}\text { As a } \\
\%\end{array}$ & & Actual & $\begin{array}{c}\text { Fore- } \\
\text { cast }\end{array}$ & Rs. bn & $\begin{array}{c}\text { As a } \\
\%\end{array}$ \\
\hline $12-\mathrm{Feb}$ & & 133.0 & & & $21-\mathrm{Feb}$ & & 133.7 & & \\
\hline $13-\mathrm{Feb}$ & & 133.3 & & & $22-\mathrm{Feb}$ & & 133.6 & & \\
\hline 14-Feb & & 133.3 & & & $23-\mathrm{Feb}$ & & 133.5 & & \\
\hline $15-F e b$ & & 133.4 & & & $24-\mathrm{Feb}$ & & 133.4 & & \\
\hline 16-Feb & & 133.6 & & & $25-\mathrm{Feb}$ & & 133.1 & & \\
\hline $17-\mathrm{Feb}$ & & 133.6 & & & $26-\mathrm{Feb}$ & & 133.1 & & \\
\hline $18-\mathrm{Feb}$ & & 133.5 & & & $27-\mathrm{Feb}$ & & 133.0 & & \\
\hline $19-\mathrm{Feb}$ & & 133.6 & & & $28-\mathrm{Feb}$ & & 132.8 & & \\
\hline $20-\mathrm{Feb}$ & & 133.7 & & & & & & & \\
\hline Sep-05 & 128.4 & 128.4 & 0.0 & 0.0 & Dec-05 & 134.3 & 133.9 & -0.4 & -0.3 \\
\hline Oct -05 & 129.4 & 129.2 & -0.2 & -0.2 & Jan-06 & 132.9 & 132.8 & -0.1 & -0.1 \\
\hline Nov-05 & 131.8 & 131.8 & 0.0 & 0.0 & Feb-06 & & 132.7 & -0.1 & -0.1 \\
\hline \multicolumn{5}{|c|}{ SER (with in sample) } & & & 1.0056 & & \\
\hline \multicolumn{5}{|c|}{ Out sample Forecast error } & & & & 0.4432 & \\
\hline
\end{tabular}

